EUROPEAN CENTRAL BANK

WORKING PAPER SERIES

N0. 322 / MARCH 2004

\title{
MODELLING INFLATION IN \\ THE EURO AREA
}

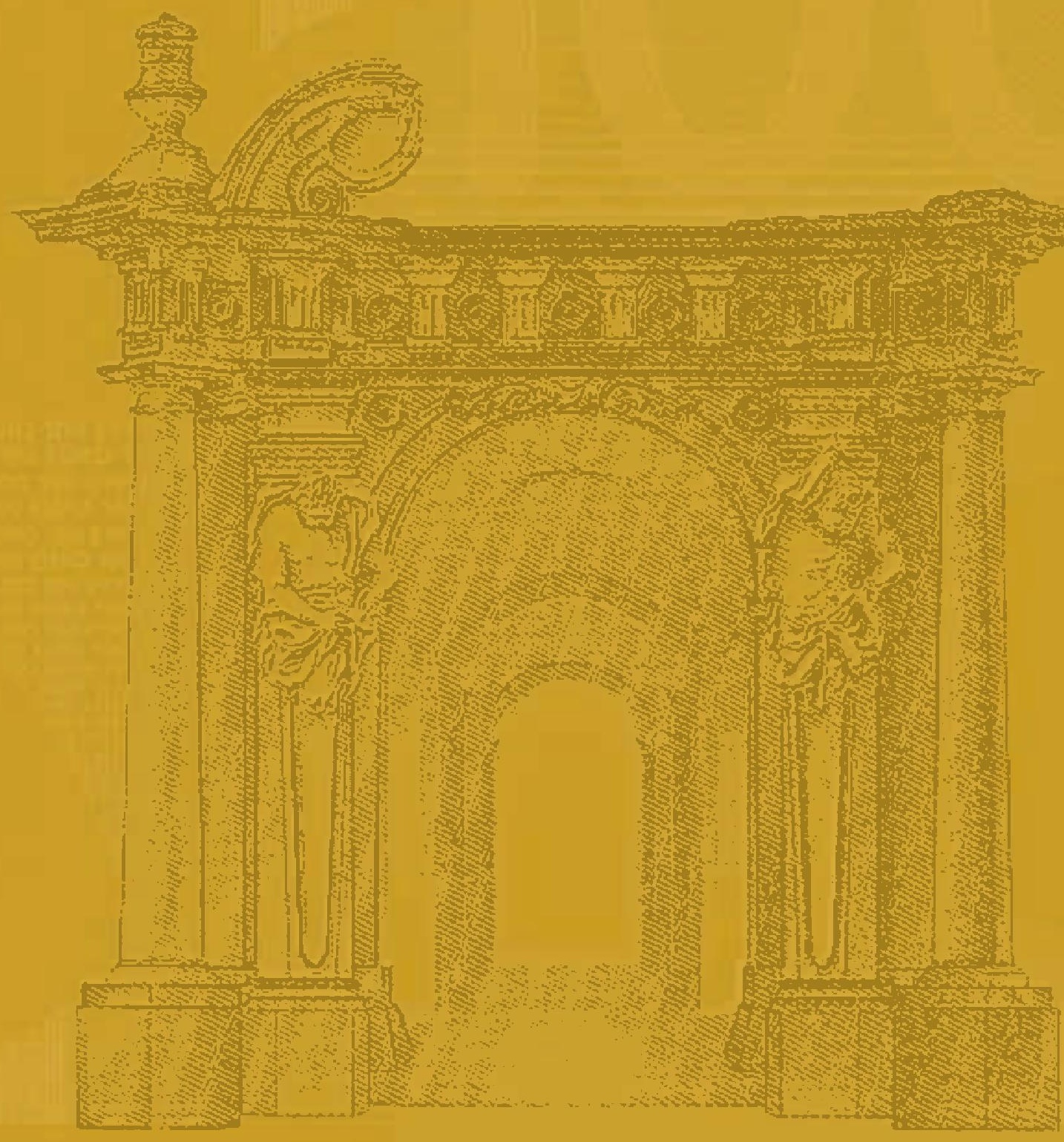




\title{
WORKING PAPER SERIES
}

N0. 322 / MARCH 2004

\author{
MODELLING \\ INFLATION IN \\ THE EURO AREA'
}

by Eilev S. Jansen ${ }^{2}$
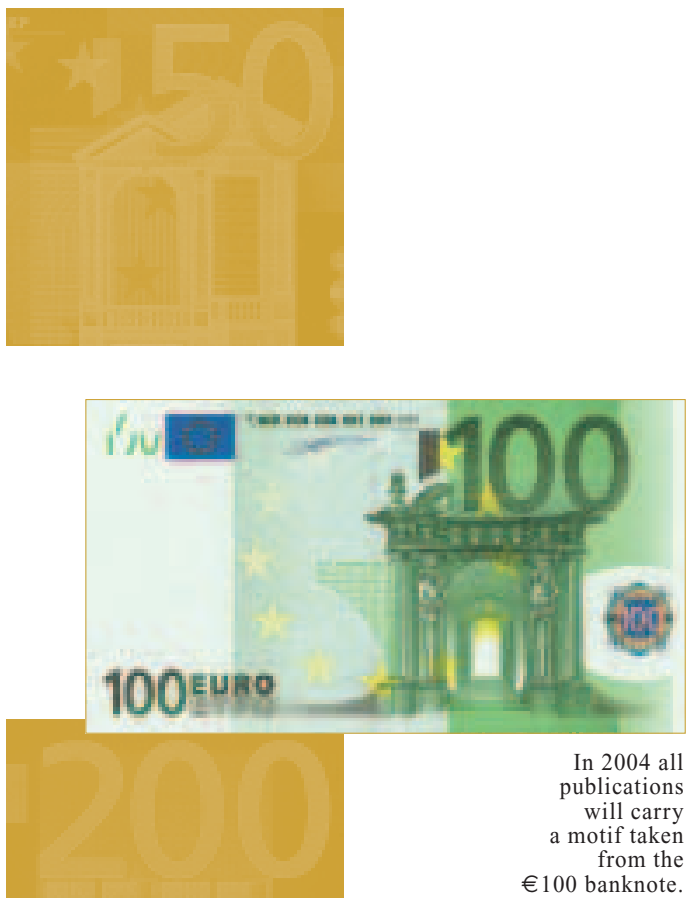

This paper can be downloaded without charge from http://www.ecb.int or from the Social Science Research Network electronic library at http://ssrn.com/abstract_id $=526985$ S.

I This paper was written as part of the project "Modelling wages and prices in the Euro area", while the author was a Research Visitor to DG Research, European Central Bank, Frankfurt from February through June 2003. I am grateful to Øyvind Eitrheim for his permission to include unpublished material from Eitrheim and Jansen (2003). While working on this project, I have received valuable data assistance from Elena Angelini and Alistair Dieppe of DG Research as well as from Mika Tujula and Focco Vijselaar of DG Economics at the ECB. An anonymous referee has provided helpful advice and comments from Christopher Bowdler, Gabriel Fagan, Jerôme Henry, Ricardo Mestre, Ragnar Nymoen and seminar participants at the ECB, Norges Bank, Norwegian University of Science and Technology, and University of California, San Diego are also gratefully acknowledged. The views expressed in this paper represent exclusively the views of the author and do not necessarily reflect those of the European Central Bank or Norges Bank. 2 Norges Bank, Norwegian University of Science and Technology, email: eilev.jansen@norges-bank.no. 


\section{드 European Central Bank, 2004}

\section{Address}

Kaiserstrasse 29

60311 Frankfurt am Main, Germany

Postal address

Postfach 160319

60066 Frankfurt am Main, Germany

Telephone

+496913440

\section{Internet}

http://www.ecb.int

Fax

+496913446000

Telex

411144 ecb d

All rights reserved.

Reproduction for educational and noncommercial purposes is permitted provided that the source is acknowledged.

The views expressed in this paper do not necessarily reflect those of the European Central Bank.

The statement of purpose for the ECB Working Paper Series is available from the ECB website, http://www.ecb.int.

ISSN 1561-0810 (print)

ISSN 1725-2806 (online) 


\section{CONTENTS}

Abstract 4

Non-technical summary 5

1 Introduction 7

2 A survey of empirical Euro area inflation models

2.1 The wage price block of the Area Wide Model (AWM)

2.2 Other approaches to inflation modelling

3 The incomplete competition model (ICM) of inflation

3.1 A framework for joint modelling of wages and prices

3.2 The core model

3.3 Modelling the steady state

3.4 The dynamic price - unit labour cost model

3.5 Valid conditioning

4 The models - evaluation and forecast comparisons

4.1 The reduced form AWM inflation equation

4.2 The reduced form ICM inflation equation

4.3 The $\mathrm{P}^{*}$ model

4.4 The New Keynesian Phillips curve

4.5 Evaluation of the inflation models' properties

4.6 Comparing the forecasting properties of the models

5 Conclusions 34

References 35

A One step forecasts - diagrams 36

B Wage price block of AWM 37

C Data 38

C.1 The AWM data series 38

C.2 Alternative data for labour input Hours worked 40

C.3 Variables specific to the $\mathrm{P} *$-model 4 II

European Central Bank

working paper series 


\begin{abstract}
The paper presents an incomplete competition model (ICM), where inflation is determined jointly with unit labour cost growth. The ICM is estimated on data for the Euro area and evaluated against existing models, i.e. the implicit inflation equation of the Area Wide model (AWM) - cf. Fagan, Henry and Mestre (2001) - and estimated versions of the (single equation) $\mathrm{P}^{*}$ model and a hybrid New Keynesian Phillips curve.

The evidence from these comparisons does not invite decisive conclusions. There is, however, some support in favour of the (reduced form) AWM inflation equation. It is the only model that encompasses a general unrestricted model and it forecast encompasses the competitors when tested on 20 quarters of one step ahead forecasts.
\end{abstract}

Keywords: inflation, incomplete competition model, Area Wide model, $P^{*}$-model, New Keynesian Phillips curve, model evaluation, forecast encompassing.

JEL classification: C22,C32,C52,C53,E31 


\section{Non-technical summary}

The merits of four different models in explaining and forecasting Euro area inflation are compared. First, we consider the wage price block of the Area Wide Model (AWM), as described in Fagan et al. (2001), which is defined within a fullblown macroeconometric model for the Euro area. The AWM treats the region as a single economy and is providing the only coherent data set available so far for the Euro area. This is a constructed data set that goes back to 1970.1. Since the Euro was introduced only 1. January 1999, the counterfactual nature of the AWM as well as the present modelling exercise is evident.

The AWM is used as a benchmark and forms a baseline for comparison with competing models of inflation. The competitors are:

- The $\mathrm{P}^{*}$-model of inflation suggested in Hallman et al. (1991), which conceives of inflation primarily as a monetary phenomenon: The model specifies a direct effect from the lagged price gap, defined as the lagged price level minus the long run equilibrium price level which is implied by a long run quantity equation. We estimate two versions of the model, one on a limited information set $\left(\mathrm{P}^{*}\right.$ proper) and one on a wider information set ( $\mathrm{P}^{*}$-enhanced). Trecroci and Vega (2002) and Gerlach and Svensson (2003) find support for the $\mathrm{P}^{*}$-model formulation on Euro area data.

- The New Keynesian Phillips curve, (NPCM), which is an inflation model with forward-looking behaviour. The model is derived theoretically from first principles in an environment of dynamically optimizing agents and has been adopted as a standard specification of the inflationary process in theoretical work on monetary policy, see e.g., Clarida et al. (1999) and Svensson (2000). Galí et al. (2001) claim to have found supporting evidence for the NPCM based on Euro area data.

- Finally, a reduced form inflation equation is derived from a dynamic version of an Incomplete Competition Model (ICM). The ICM, which entails joint modelling of wages and prices, has been successfully used to model the inflationary process in small open economies like UK and Norway. This model has not previously been adopted for the Euro area. The econometric approach follows a stepwise procedure, where the outcome can be seen as a product of interpretation and formal testing: We first consider an information set of wages, prices and an appropriate selection of conditioning variables like output gap, unemployment, productivity, import prices, etc. It turns out that the data rejects the long run restrictions from theory in this case. Only when we model the long run steady state equations with prices and unit labour costs as the endogenous variables do we find empirical support for the theory restrictions.

The results of the model comparisons should be interpreted with some caution: The versions of the $\mathrm{P}^{*}$-model we are estimating, which are related to the work of Gerlach and Svensson (2003), presume that there is a clearly defined monetary policy for the economy under study. This assumption is not favoured by adopting an observation period which starts nearly 30 years before the introduction of the Euro. Likewise, the ICM - with its focus on the labour market influx on inflation, 
is probably a better model description of the national economies than for the Euro area.

Notwithstanding this, some comparative advantages seem to emerge from the model evaluation and the forecast comparisons in favour of the (reduced form) AWM inflation equation: It is the only model that encompasses a general unrestricted model and it forecast encompasses the competitors when tested on 20 quarters of one step ahead forecasts. The $\mathrm{P}^{*}$-model - based on the extended (AWM) information set - forecast encompasses the other models based on 36 quarters of one step forecasts. In that context the NPCM appears to be a particularly poor model.

The results of the forecast competition are in accordance with the model evaluation. Generally, we find that the models that are derived from the wider information sets (AWM and the enhanced $\mathrm{P}^{*}$-model) do better in forecasting than those based on a narrower information set, mainly prescribed by theory, like the $\mathrm{P}^{*}$-model proper and the NPCM. 


\section{Introduction}

The purpose of this paper is two-fold. First, we investigate empirically whither inflation in the Euro area can be adequately described by a dynamic version of the incomplete competition model (ICM hereafter) due to Kolsrud and Nymoen (1998), with reference to the original contribution by Layard and Nickell (1986), see also Layard et al. (1991) and Carlin and Soskice (1990). Second, we evaluate this model against existing models, which include a (reduced form) inflation equation from the Area Wide model (AWM) of the European Central Bank and estimated versions of the $\mathrm{P}^{*}$-model and a hybrid New Keynesian Phillips curve model of inflation.

While the ICM - which entails joint modelling of wages and prices - has been successfully used to model the inflationary process in small open economies like UK and Norway ${ }^{1}$, many researchers addressing inflation in the Euro area have opted for approaches which either amounts to modelling inflation as a single equation or as part of very small systems. By contrast, the price block of the AWM, as described in Fagan et al. (2001), is defined within a full-blown macroeconometric model for the Euro area, even though the equations for wage growth and inflation are estimated by single equation methods. Moreover, the AWM is providing the only coherent data set available so far for the Euro area, and hence it is the obvious benchmark and point of reference for the current investigation.

Inflation is a many-faceted phenomenon, and models that includes only a few dimensions, e.g., the output gap and expectations of the future rate of inflation, are less likely to be able to characterize the data, as demonstrated in Bårdsen et al. (2004b). Econometric work that view inflation as resulting from disequilibria in many markets fare much better, see Hendry (2001) and Juselius (1992). Our motivation for choosing ICM as a starting point is therefore that, at a minimum, foreign and domestic aspects of inflation have to modelled jointly, and that the inflationary impetus from the labour market - the battle of markups between unions and monopolistic firms - needs to be represented in the model.

The ICM is described in Section 3.2. The econometric approach follows a stepwise procedure, where the outcome can be seen as a product of interpretation and formal testing: We first consider an information set of wages, prices and an appropriate selection of conditioning variables like output gap, unemployment, productivity, import prices, etc. It turns out that the data rejects the long run restrictions from theory in this case. Only when we model the long run steady state equations with prices and unit labour costs as the endogenous variables do we find empirical support for the theory restrictions.

The incomplete competition model of prices and unit labour costs is tested for weak exogeneity in Section 3.5. In Section 4 we derive reduced form inflation equations based on the ICM and on the wage and price block of the AWM in order to compare forecasts based on these equations with forecasts from two single equation inflation models: the $\mathrm{P}^{*}$-model and the New Keynesian Phillips curve. These models are presented in the second part of Section 2, after a survey of the wage and price block of the Area Wide model is given below. Model evaluation and forecast encompassing tests of the estimated models are presented in Sections 4.5 and 4.6. Section 5 concludes.

\footnotetext{
${ }^{1}$ See Bårdsen et al. (1998) and Bårdsen et al. (2003).
} 


\section{A survey of empirical Euro area inflation models}

\subsection{The wage price block of the Area Wide Model (AWM)}

The unique feature of the Area Wide Model is that it treats the Euro area as a single economy. Since the Euro was introduced only 1. January 1999 and the information set underlying the estimation of the model - as documented in Fagan et al. (2001) - is a constructed data set covering the period 1970.1 - 1998.4, the counterfactual nature of this modelling exercise is evident.

The AWM is used for forecasting purposes and the model has been specified to ensure that a set of structural economic relationships holds in the long run. It is constrained to be consistent with the neoclassical steady state in which the long run output is determined via a production function by exogenous technological progress and the available factors of production, where the growth rate of labour force is exogenous. Money is neutral in the long run and the model's long run properties is further pinned down by an exogenous NAIRU.

Our focus is on the modelling of wages and prices. Whereas the long run equilibria are largely determined by a priori considerations through the output production function and the exogenous growth rates in factor productivity, the labour force and the NAIRU, the short run is modelled empirically as (single equation) Equilibrium Correction models. The empirical models are reestimated in this paper on an extended data set (1970.1-2000.4) and the results, which do not deviate much from those in Fagan et al. (2001), are found in Appendix B.

Wages are modelled as a Phillips curve in levels, with wage growth depending on the change in productivity, current and lagged inflation - in terms of the consumption deflator $p_{t}$ - and the deviation of the unemployment $u_{t}$ from its NAIRU level $\bar{u}_{t}$, i.e. $\left(u_{t}-\bar{u}_{t}\right)$ defines the equilibrium correction term, ecmw $w_{t}^{A W M}$. Inflation and productivity changes enter with unit coefficients, so the equation is expressed with the change in the wage share $\Delta w s_{t}$, which equals the change in real unit labour cost, $\Delta u l c_{t}-\Delta p_{t}$, as left-hand side variable. Here, and in the rest of the paper, natural logarithms of variables are denoted by lower-case symbols.

The output price or gdp at factor costs, $q_{t}$, is a function of trend unit labour costs, $\overline{u l}_{t}$, both in the long run (levels) and the short run (changes). The equilibrium correction term equals $\left(q_{t}-\left(\overline{u l c}_{t}-(1-\beta)\right)\right)$, where $(1-\beta)$ is the elasticity of labour in the output production function, thus linking the long run real equilibrium to the theoretical steady state. The markup is also influenced by an output gap and the import price inflation $\left(\Delta p i_{t}\right)$ has short run effects on $\Delta q_{t}$. Finally, the consumer price inflation (i.e. the consumption deflator) $\Delta p_{t}$ is determined by the gdp deflator at market prices, and import prices, both in the short run and in the long run (with estimated weights equal to 0.94 and 0.06 , respectively). There is also a small effect of world market raw materials prices in this equation. Noting that the gdp deflator at market prices by definition equals gdp at factor prices corrected for the rate of indirect taxation $\left(q_{t}+t_{t}\right)$, we find by substituting for $q_{t}$ that the equilibrium correction term for $\Delta p_{t}$ can be written as

$$
e c m p_{t}^{A W M}=p_{t}+0.59 \cdot 0.94-0.94 \overline{u l c}_{t}-0.06 p i_{t}-0.94 t_{t}
$$


In the actual forecasting process the ECB is also maintaining country models for the five largest countries in the Euro area: France, Germany, Italy, the Netherlands and Spain. The models are linked together via trade flows into a Multi-country model (the ESCB-MCM). Interestingly, the structure of the wage and price block in each of these country models are mirror images of the AWM wage and price block, except for Spain which has a endogenous NAIRU determined by the real exchange rate influencing a non-constant markup in the inflation equation, see Willman and Estrada (2002).

Is inflation a stationary variable? The main data series underlying the AWM are documented in Fagan et al. (2001), see Appendix C. As always, the question of whether the inflation and the other nominal variables are stationary $\mathrm{I}(0)$ or nonstationary $\mathrm{I}(1)$ variables is a crucial modelling issue. Formal ADF tests on the nominal series of wages and prices support the view of Juselius (2003) that they are $\mathrm{I}(2)$, i.e. that the level series need to be differenced twice in order to become stationary. ${ }^{2}$ In the majority of the empirical studies that are carried out so far on Euro area data, however, it is implicitly or explicitly assumed that the series for prices and wages can be treated as $\mathrm{I}(1) .{ }^{3}$ This is also this assumption we make throughout the current paper, bearing in mind that an alternative interpretation of the ADF tests is that the nominal levels variables are $\mathrm{I}(1)$ with breaks in means which make them look like I(2). ${ }^{4}$ Hendry (2001) points out that if the levels are integrated once with superimposed major breaks then the measurements thereof have $\mathrm{I}(1)$ deviations from the desired theoretical counterparts. Hence inflation is treated as $\mathrm{I}(0)$ with breaks, but measured with an $\mathrm{I}(0)$ error. This is also the view taken in Bowdler and Jansen (2004), who model inflation in the Euro area as a markup over costs, corrected for indirect taxation and a trend. They extend

\footnotetext{
${ }^{2}$ Juselius (2003) estimates a cointegrated VAR model to determine wages, prices, productivity and unemployment using the Euro area data. She assumes that the nominal variables follow I(2) processes in levels, and she models inflation, real wages, productivity, unemployment, an internal price wedge (the difference between consumer and producer prices, $(p-q)$ ) and the real exchange rate $\left(e^{r e}\right)$ as non-stationary I(1) processes. Interestingly, she finds a marked regime shift at the introduction of the EMS and she carries out her empirical analysis separately for the two regimes (1970.2 - 1980.1 and 1982.1 - 1998.1, respectively).

${ }^{3}$ This is the case for Fagan et al. (2001). It is also true for the analysis of Euro Area NAIRU in Fabiani and Mestre $(2000,2001)$, who report tests indicating that price levels are I(2). Also Angelini et al. (2001), who study Euro area inflation as a diffusion process derived from national wage and price inflation series, find that the HICP and the deflator for private consumption are $\mathrm{I}(2)$ variable by formal tests. They maintain an a priori belief that there have been deterministic breaks series in the 1980s and that an increasing variance on inflation is not compatible with the notion of convergence towards a lower inflation rate in the area in the 1990s. Fabiani and Morgan (2003) report evidence that the private consumption deflators for Germany, France, Spain, Italy and the Netherlands - and for their aggregate - are I(1) for a sample covering 1982.1 -2000.4.

${ }^{4}$ In a study of inflation persistence in Germany, France and Italy, and in their aggregate (representing 60 per cent of the Euro area), Batini (2002) splits the samples in several subperiods and measures inflation as deviations from period specific means. This is one way of accommodating the assumption of deterministic breaks in mean and she finds that her inflation measures are stationary according to formal ADF tests. Recently, Levin and Piger (2003) find that deterministic breaks in the intercept term can explain the persistence in the series as measured by univariate autoregressive models for inflation in 12 OECD countries for the period $1984-2002$.
} 
the standard approach by allowing for a time-varying intercept in the model for inflation, which can be interpreted as approximating the behaviour of deterministic shifts in the price-cost markup. ${ }^{5}$

\subsection{Other approaches to inflation modelling}

Inflation models that rely heavily on a priori theory have flourished in recent years. Such models often consider only a limited information set as defined by the theory. In the following we shall look at two examples that are representative for the literature: On the one hand, the New Keynesian Phillips curve, which is an inflation model that is derived theoretically from first principles in an environment of dynamically optimizing agents and has been adopted as a standard specification of the inflationary process in theoretical work on theory of monetary policy, see e.g., Clarida et al. (1999) and Svensson (2000). Second, we will consider monetary models of inflation that conceive of inflation primarily as a monetary phenomenon, in particular the $\mathrm{P}^{*}$-model, which relates the steady state of the price level to the quantity theory of money. Both the New Keynesian Phillips curve and the $\mathrm{P}^{*}$-model have recently been explored empirically on Euro area data.

The New Keynesian Phillips curve The New Keynesian Phillips curve states that inflation is explained by expected inflation one period ahead $\mathrm{E}\left(\Delta p_{t+1} \mid \mathcal{I}_{t}\right)$, and excess demand or marginal costs $x_{t}$ (e.g., output gap, the unemployment rate or the wage share in logs):

$$
\Delta p_{t}=b_{p_{1}} \mathrm{E}\left(\Delta p_{t+1} \mid \mathcal{I}_{t}\right)+b_{p 2} x_{t} .
$$

Roberts (1995) has shown that several New Keynesian models with rational expectations have (2) as a common representation-including the models of staggered contracts developed by Taylor $(1979,1980)$ and Calvo (1983), and the quadratic price adjustment cost model of Rotemberg (1982). Galí and Gertler (1999) have given a formulation of the NPC in line with Calvo's work: They assume that a firm takes account of the expected future path of nominal marginal costs when setting its price, given the likelihood that its price may remain fixed for multiple periods. This leads to a version of the inflation equation (2), where the forcing variable $x_{t}$ is the representative firm's real marginal costs (measured as deviations from its steady state value). They argue that the wage share (the labour income share) $w s_{t}$ is a plausible indicator for the average real marginal costs, which they use in empirical analysis.

Models like (2), with forward expected inflation, implies a jump behaviour of inflation which is at odds with observed behaviour of inflation. This have led to a "hybrid" New Keynesian Phillips curve model, which heuristically assumes the existence of both forward- and backward-looking agents, e.g. Galí and Gertler (1999) suggest a hybrid Phillips curve that allows a subset of firms to have a backwardlooking rule to set prices, which nests (2) as a special case. This amounts to the

\footnotetext{
${ }^{5}$ The time-varying intercept can also be interpreted as a factor that cointegrates with an otherwise nonstationary markup. Tests indicate that a linear combination of the intercept and the price-cost markup gives a long run relationsship with residuals that are closer to stationarity.
} 
specification

$$
\Delta p_{t}=b_{p 1}^{f} \mathrm{E}\left(\Delta p_{t+1} \mid \mathcal{I}_{t}\right)+b_{p 1}^{b} \Delta p_{t-1}+b_{p 2} x_{t} .
$$

Galí et al. (2001) estimate (3) for the Euro area in several variants - using different inflation measures, different normalization rules for GMM estimation, including additional lags of inflation in the equation and splitting the sample. They find that the overall picture remains unchanged. Marginal costs have a significant impact on short run inflation dynamics and forward looking behaviour is always found to be important.

In Smets and Wouters (2002) a New Keynesian Phillips curve is estimated as part of a stochastic dynamic general equilibrium model for the Euro area. The inflation equation is estimated as part of a simultaneous system with nine endogenous variables in a Bayesian framework using Markov-chain Monte Carlo methods, and the authors find parameter estimates which are in line with Galí et al. (2001) for a hybrid version of the New Keynesian Phillips curve (with weights 0.72 and 0.28 on forward and lagged inflation, respectively).

Also, Coenen and Wieland (2002) investigate whether the observed inflation dynamics in the Euro area (as well as in the US and Japan) are consistent with microfoundations in the form of staggered nominal contracts and rational expectations. On Euro area data, they find that the fixed period staggered contract model of Taylor outperforms the New Keynesian Phillips curve specification based on Calvo-style random duration contracts and they claim support for the hypothesis of rational expectations. ${ }^{6}$.

The New Keynesian Phillips curve has come under increasing critique both on theoretical and empirical grounds. Bårdsen et al. (2004b) demonstrate that the dynamic properties of the New Keynesian Phillips curves depend not only on (2) or (3), but also on the specification of a $x_{t}$-process. They show that it is useful to extend the empirical evaluation from the single equation to a system consisting of the rate of inflation and the forcing variable. In the case of the Euro area they show that the wage share is not an exogenous driving variable and that the significance of the forward term in (3) disappears in well-specified models, i.e. due to omitted variables in the inflation equation or if instruments, that the agents should know of, are introduced. In an influential paper, Rudd and Whelan (2004) show that the tests of forward-looking behaviour which Galí and Gertler (1999) rely on, have very low power against alternative, but non-nested, backward-looking specifications, and demonstrate that results previously interpreted as evidence for the New Keynesian model are also consistent with a backward-looking Phillips curve. Rudd and Whelan develop alternative, more powerful tests, which exhibit a very limited role for forward-looking expectations. This critique is further reinforced by a point made by Mavroeidis (2002), namely that the hybrid New Keynesian Phillips curve suffers from underidentification, and that in empirical applications identification is achieved by confining important explanatory variables to the set of instruments, with misspecification as a results of this practice.

\footnotetext{
${ }^{6}$ Coenen and Wieland adopt a system's approach, namely an indirect inference method due to Smith (1993), which amounts to fitting a constrained VAR in inflation, output gap and real wages, using the Kalman filter to estimate the structural parameters such that the correlation structure matches those of an unconstrained VAR in inflation and output gap.
} 
Monetary models of inflation In the $\mathrm{P}^{*}$-model (see Hallman et al. (1991)) the long run equilibrium price level is defined as the price level that would result with the current money stock, $m_{t}$, provided that output was at its potential (equilibrium level), $y_{t}^{*}$, and that velocity, $v_{t}=p_{t}+y_{t}-m_{t}$, was at its equilibrium level $v_{t}^{*}$ :

$$
p_{t}^{*} \equiv m_{t}+v_{t}^{*}-y_{t}^{*}
$$

The postulated inflation model is given by

$$
\Delta p_{t}=\mathrm{E}\left(\Delta p_{t} \mid \mathcal{I}_{t-1}\right)+\alpha_{p}\left(p_{t-1}-p_{t-1}^{*}\right)+\beta_{z} z_{t}+\varepsilon_{t}
$$

where the main explanatory factors behind inflation are inflation expectations, $\mathrm{E}\left(\Delta p_{t} \mid \mathcal{I}_{t-1}\right)$, the price gap, $\left(p_{t-1}-p_{t-1}^{*}\right)$, and other variables denoted $z_{t}{ }^{7}$ Note that if we replace the price gap in (5) with the output gap we obtain the New Keynesian Phillips Curve model (2) discussed in the previous section, with the expectations term backdated one period.

In order to calculate the price gap one needs to approximate the two equilibria for output, $y_{t}^{*}$, and velocity, $v_{t}^{*}$, respectively. The price gap, $\left(p_{t}-p_{t}^{*}\right)$, is obtained by subtracting $p_{t}$ from both sides of (4) and applying the identity $v_{t} \equiv p_{t}+y_{t}-m_{t}$. It follows that the price gap is decomposed into the velocity gap, $\left(v_{t}-v_{t}^{*}\right)$, minus the output gap, $\left(y_{t}-y_{t}^{*}\right)$.

$$
\left(p_{t}-p_{t}^{*}\right)=\left(v_{t}-v_{t}^{*}\right)-\left(y_{t}-y_{t}^{*}\right)
$$

The $\mathrm{P}^{*}$-model can alternatively be expressed in terms of the real money gap, $r m_{t}-$ $r m_{t}^{*}$, where $r m_{t}^{*}=m_{t}-p_{t}^{*}$. The inverse relationship holds trivially between the real money gap and price gap, i.e., $\left(r m_{t}-r m_{t}^{*}\right)=-\left(p_{t}-p^{*}\right)$, and thus the $\mathrm{P}^{*}$-model predicts that there is a direct effect on inflation from the lagged real money gap $\left(r m-r m^{*}\right)_{t-1}$. Moreover, in the $\mathrm{P}^{*}$-model, fluctuations in the price level around its equilibrium, $p_{t}^{*}$, are primarily driven by fluctuations in velocity and output.

The real money gap. Figures 14 and 15 in Appendix C show the "price gap" $\left(p-p^{*}\right)_{t}$ and the "real money" gap $\left(r m-r m^{*}\right)_{t}$ along with the corresponding level series, which we have employed in the empirical estimation of the $\mathrm{P}^{*}$-model in Section 4.3. We have applied Hodrick-Prescott (HP) filters ${ }^{8}$ to derive measures for $y_{t}^{*}$ and $v_{t}^{*}$, and in doing so, we have used $\lambda=1600$ to smooth output series $y_{t}^{*}$ and $\lambda=400$ to smooth velocity $v_{t}^{*}$. Then $p_{t}^{*}$ can be calculated from (4) above, as well as the price- and real money gaps.

Reference path for money growth and inflation. Another defining characteristic of recent studies adopting the $\mathrm{P}^{*}$-model is that inflation is assumed to be influenced by $\Delta_{4}$ pgap $_{t}$, which is the change in the difference between the actual inflation $\Delta_{4} p_{t}$ and a reference or target path $\Delta_{4} \widetilde{p}_{t}$, and also by an analogous variable for money growth, $\Delta_{4}$ mgap $_{t}$. The reference path for money growth $\Delta_{4} \widetilde{m}_{t}$ is calculated in a similar way as suggested in Gerlach and Svensson (2003), referred to below. If we know the inflation target (or reference path for inflation in the case when no explicit target exists), we can calculate the corresponding reference path for money growth as follows (see Bofinger (2000)):

\footnotetext{
${ }^{7}$ Confer also Eitrheim (2003) and chp. 8 in Bårdsen et al. (2004a).

${ }^{8}$ See Hodrick and Prescott (1997).
} 


$$
\Delta_{4} \widetilde{m}_{t}=\Delta_{4} \widetilde{p}_{t}+\Delta_{4} y_{t}^{*}-\Delta_{4} v_{t}^{*}
$$

The equilibrium paths for output, $y_{t}^{*}$, and velocity, $v_{t}^{*}$ are calculated by the HP-filter, as suggested above. In our empirical estimates of the $\mathrm{P}^{*}$-model we have simply let the reference value for inflation vary with the actual level of smoothed inflation. The heuristic interpretation is that the monetary authorities changed the reference path according to the actual behaviour, adapting to the many shocks to inflation in this period and we calculate the reference value of inflation with a HPfilter with a large value of the parameter which penalizes non-smoothness, i.e., we set $\lambda=6400$ to avoid volatility in $\Delta_{4} \widetilde{p}_{t} . \Delta_{4} \widetilde{m}_{t}$ follows from $(7)$ as do $\Delta_{4}$ pgapt and $\Delta_{4}$ mgap $_{t}$.

Gerlach and Svensson (2003) have estimated a variant of the $\mathrm{P}^{*}$-model (5), and they find empirical support for the $\mathrm{P}^{*}$-model on aggregated data for the Euro area. In this study Gerlach and Svensson introduce and estimate a measure for the inflation target in the Euro area as a gradual adjustment to the (implicit) inflation target of the Bundesbank, and they interpret the gradual adjustment as a way of capturing a monetary policy convergence process in the Euro area throughout their estimation period $(1980.1-2001.2)^{9}$.

Gerlach and Svensson (2003) find a significant effect of the energy component of consumer price index on inflation measured by the total consumer price index, and when they include the output gap in (5), in addition to the real money gap, both gaps come out equally significant, indicating that each is an important determinant of future price changes. By contrast, they find that the Eurosystem's money-growth indicator defined as the gap between current M3 growth and its reference value has little predictive power beyond that of the output gap and the real money gap.

In an earlier study, Trecroci and Vega (2002) reestimate the AWM equation for the gdp deflator at factor prices for the period 1980.4 - 1997.4, and they find that (an earlier version of) the Gerlach and Svensson $\mathrm{P}^{*}$ equation (without output gap) outperforms the AWM price equation (for $q_{t}$ ) in out of sample forecasts for the period 1992.1 - 1997.4 at horizons ranging from 1 to 8 periods ahead. ${ }^{10}$ Likewise, Nicoletti Altimari (2001) finds support for the idea that monetary aggregates contain substantial information about future price developments in the Euro area and that the forecasting performance of models with money-based indicators improves as the forecast horizon is broadened.

\footnotetext{
${ }^{9}$ In Appendix $\mathrm{C}$ we have plotted their measures against the HP-filtered measures for the inflation target $\Delta_{4} \widetilde{p}_{t}$ and the money reference path $\Delta_{4} \widetilde{m}_{t}$ and the corresponding gaps $\Delta_{4} p g a p_{t}$. and $\Delta_{4}$ mgap $_{t}$, see Figures 16 - 17 .

${ }^{10}$ Trecroci and Vega estimate the $\mathrm{P}^{*}$-model within a small VAR, which previously has been analysed in Coenen and Vega (2001).
} 


\section{The Incomplete Competition model (ICM) of inflation}

\subsection{A framework for joint modelling of wages and prices}

One way of thinking about modelling inflation is to distinguish between a core model of wages and prices and an embedding environment of feed-back variables, non-modelled variables and policy instruments as is illustrated in Figure 1.

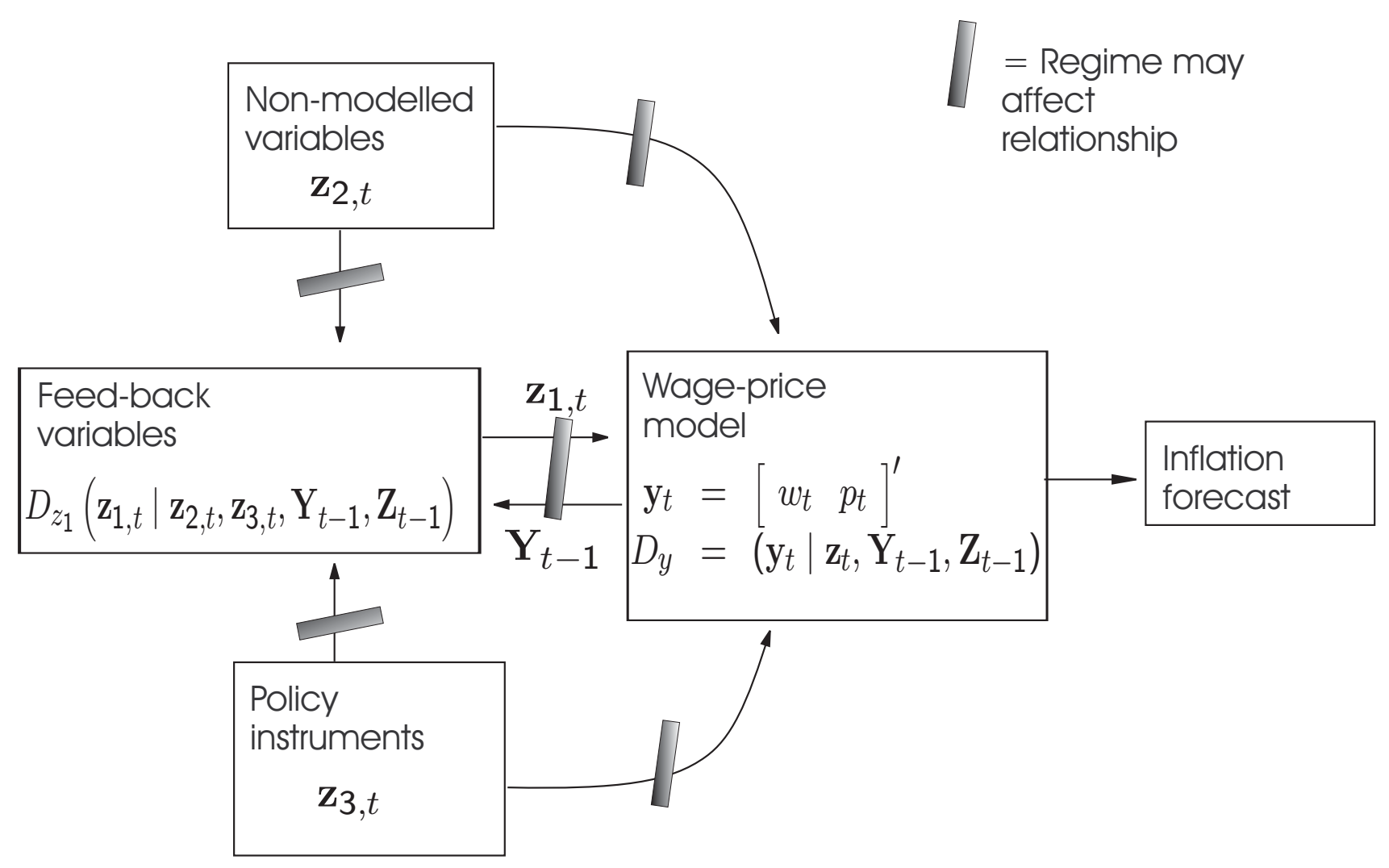

Figure 1: Model based inflation forecasts.

The simultaneous wage-price model is $D_{y}\left(\mathbf{y}_{t} \mid \mathbf{z}_{t}, \mathbf{Y}_{t-1}, \mathbf{Z}_{t-1}\right)$, where $\mathbf{y}_{t}=$ $\left[\begin{array}{ll}w_{t} & p_{t}\end{array}\right]^{\prime}$, the vector $\mathbf{z}_{t}$ contains all conditioning variables, and $\left(\mathbf{Y}_{t-1}, \mathbf{Z}_{t-1}\right)$ collects all lagged values of $\mathbf{y}_{t}$ and $\mathbf{z}_{t}$. The variables in $\mathbf{z}_{t}$ are partitioned into $\left[\begin{array}{llll}\mathbf{z}_{1, t} & \mathbf{z}_{2, t} & \mathbf{z}_{3, t}\end{array}\right]^{\prime}$, where $\mathbf{z}_{1, t}$ denote feedback variables, $\mathbf{z}_{2, t}$ are non-modelled variables, and $\mathbf{z}_{3, t}$ are monetary policy instruments. Lagged values are partitioned correspondingly, $\mathbf{Z}_{t-1}=$ $\left(\mathbf{Z}_{1, t-1}, \mathbf{Z}_{2, t-1}, \mathbf{Z}_{3, t-1}\right)$, and in the figure $\mathbf{z}_{i}=\left(\mathbf{z}_{i, t}, \mathbf{Z}_{i, t-1}\right)$.

In the next section we will present a core model of inflation as a wage price system conditional on output, productivity, unemployment and import prices (i.e. the exchange rate) as in Bårdsen et al. (2003), and we demonstrate how this model can be written in terms of prices and unit labour costs conditional on output, unemployment and foreign prices, which is the form on which we estimate the ICM model in Sections 3.3 and 3.4.

Arriving at a cointegrated VAR in unit labour costs, prices and the conditioning variables - the next step is general-to-specific modelling of a data congruent specification of the core system, through testing the overidentifying restrictions of 
a sequence of restricted dynamic models against the unrestricted reduced form. In section 3.5, the conditioning variables are tested for valid conditioning (weak exogeneity).

In Bårdsen et al. (2003) the focal point is the core model's invariance to changing monetary policy and in Figure 1 it is indicated that regime shifts may induce non-constancies in the parameters of the model. This aspect is not covered in the current paper, and it is a topic for further research.

\subsection{The core model}

The wage-price model $D_{y}\left(\mathbf{y}_{t} \mid \mathbf{z}_{t}, \mathbf{Y}_{t-1}, \mathbf{Z}_{t-1}\right)$ we want to explore in the present paper is an extension of Kolsrud and Nymoen (1998) where the inflation process is modelled as emerging from the labour market. Assuming a Cobb Douglas production technology and that firms set their prices $q_{t}$ in the long run as a stationary markup over unit labour costs gives the cointegrating relationship:

$$
q_{t}-(w-p r)_{t}=m_{q, t} \sim I(0)
$$

where integration of order zero is denoted $I(0)$. The wage rate is $w_{t}$ (which includes payroll taxes), and $p r_{t}$ is productivity. A slight generalisation is to let the markup $m_{q, t}$ on average cost depend on demand relative to capacity. If we in addition invoke Okun's law relationship to replace capacity utilisation with the rate of unemployment (assuming that $u_{t}$ is $\mathrm{I}(0)$ or $\mathrm{I}(0)$ with breaks), the equation (8) can be written as

$$
q_{t}-(w-p r)_{t}=m_{q, t}+\vartheta u_{t}, \quad \vartheta \geq 0
$$

At first sight, (8) seems to exclude an important channel for import prices on inflation. However, in the following we are focusing on nominal wages and the consumer price index $p_{t}$, defined as

$$
p_{t} \equiv \phi q_{t}+(1-\phi) p i_{t}+\eta t_{t}, 0<\phi<1, \quad 0<\eta \leq 1,
$$

where the import price index $p i_{t}$ naturally enters. The parameter $\phi$ measures of the openness of the economy. Also, the size of the parameter $\eta$ will depend on how much of the retail price basket is covered by the indirect tax-rate index $t_{t}$. Conveniently, and in accordance with our discussion in Section 2.1, all variables defined so far (except $u_{t}$ ) are assumed to be $I(1)$.

Conflicting real-wage claims are inherent in economies where market forces are impeded by bargaining between organizations and intervention by the government in most European economies. Derived from the bargainers' respective utility functions and budget constraints, as in Hoel and Nymoen (1988), a long run wage equation can be written as:

$$
w_{t}-q_{t}-\omega(p-q)_{t}-\iota p r_{t}-\varpi u_{t}=m_{w, t} \sim I(0),
$$

The real wage faced by firms is affected by producer prices $q_{t}$ and productivity $p r_{t}$. The real wage faced by employees can be affected by the wedge $(p-q)_{t}$. The unemployment rate, $u_{t}$, represents the degree of tightness in the labour market which influences the outcome of the wage bargain. Generally, $m_{w, t}$ depends on 
factors on both the union and firm side as well as of institutional factors (degree of centralization, incomes policies, generosity of the unemployment insurance system, extent and coverage of labour market programmes, cf. Layard et al. (1991) where these factors are given a thorough treatment. $)^{11}$

The long run model is (9) and (11), augmented with (10) and solving out for producer prices $q_{t}$ then gives a model in wages $w_{t}$ and consumer prices $p_{t}$ only:

$$
\begin{aligned}
w_{t}= & m_{w, t}+\frac{1-\omega(1-\phi)}{\phi} p_{t} \\
& +\iota p r_{t}-\varpi u_{t}-\frac{(1-\omega)(1-\phi)}{\phi} p i_{t}+\frac{(1-\omega) \eta}{\phi} t_{t} \\
p_{t}= & -\phi m_{q, t}+\phi\left(w_{t}-p r_{t}\right) \\
& -\phi \vartheta u_{t}+(1-\phi) p i_{t}+\eta t_{t},
\end{aligned}
$$

that implicitly implies non-linear cross-equation restrictions in terms of $\phi .^{12}$

As discussed in Section 3.3 below, in the following we will use unit labour costs as our wage indicator. This amounts to setting $\iota=1$ in (12), which means that in the long run unions get full compensation for productivity gains. ${ }^{13}$ Making this assumption changes (12) and (13) into:

$$
\begin{aligned}
u l c_{t} & =m_{w, t}+\frac{1-\omega(1-\phi)}{\phi} p_{t}-\varpi u_{t}-\frac{(1-\omega)(1-\phi)}{\phi} p i_{t}+\frac{(1-\omega) \eta}{\phi} t_{t} \\
p_{t} & =-\phi m_{q, t}+\phi u l c_{t}-\phi \vartheta u_{t}+(1-\phi) p i_{t}+\eta t_{t}
\end{aligned}
$$

Simply by viewing (9) and (11) as a pair of simultaneous equations, it is clear that the system is unidentified in general. However, if the high level of aggregation

\footnotetext{
${ }^{11}$ As noted above, we include the payroll taxes paid the employer in the wage avariable, implicitly assuming that the unions see the social security contribution by the firms as equivalent to ordinary wage.

${ }^{12}$ The two relationships (12) and (13) are still not identified in general. However, as discussed below, $\omega=1$ and $\vartheta=0$, are a set of necessary conditions for identification which is suited for the case of aggregated wages and prices.

In Bårdsen et al. (2004a) we refer to yet two other "identification schemes" which have proven themselves useful in our own modelling of both disaggregate and aggregate data:

a) In many applications, especially on sectorial data, formal tests of cointegration support only one cointegration relationship, thus either one of residuals from (8) and (11), which are candidate equilibrium correcting terms, is $\mathrm{I}(1)$, instead of both being $\mathrm{I}(0)$. In this case it is usually possible to identify the single cointegrating equation economically by restricting the coefficients, and by testing the weak exogeneity of one or more of the variables in the system.

b) The no wedge case also apply to a sectorial wage-price system: Assume that the price markup is not constant as assumed above, but a function of the relative price (via the price elasticity). In this case, the price equation (9) is augmented by the real exchange rate $p_{t}-p i_{t}$. If we furthermore assume that $\omega=0$, (no wedge in wage formation) and $\vartheta=0$ (normal cost pricing), identification of both long run schedules is logically possible.

${ }^{13}$ Juselius (2003) finds support for a long run equation indicating the unions only get 50 percent compensation for productivity gains over the period $1982-2000$.
} 
means that $\omega$ can be set to unity (while retaining cointegration) $)^{14}$, and that there is normal cost pricing in the aggregated price relationship identification is again possible. Thus $\omega=1$ and $\vartheta=0$ represents one set of necessary (order) restrictions for identification in this case:

$$
\begin{aligned}
u l c_{t} & =m_{w, t}+p_{t}-\varpi u_{t} \\
p_{t} & =-\phi m_{q, t}+\phi u l c_{t}+(1-\phi) p i_{t}+\eta t_{t} .
\end{aligned}
$$

Our strategy is first to model the steady states along these lines - as a product of interpretation and formal testing - and then go on to model the dynamic equations for unit labour costs and inflation jointly as equilibrium correcting models.

\subsection{Modelling the steady state}

As we have alluded to above, our first attempt has been to model the long run according to equations (12)-(13), which entails that the variables that contain the long run real wage claims equations are collected in the vector $\left[\begin{array}{lllll}w & p & p r & p i & u\end{array}\right]$. The wage variable $w$, is defined as in AWM as total compensation to employees (including employers social security contributions) divided by total employment. The productivity variable $p r$ is defined as gdp divided by total employment. The price index $p$ is measured by the private consumption deflator and import prices $p i$ are the imports deflator, including intra Euro area trade, and $u$ is the log of the unemployment rate.

In addition to the variables in the wage-claims part of the system, we include the indirect tax rate, $t$, and $g a p_{t-1}$ - the lagged output gap measured as deviations from the trend obtained by the Hodrick-Prescott filter. Dummy variables found significant in the wage and price block of AWM Fagan et al. (2001) are included in the conditioning set. ${ }^{15}$ This system, where wages and prices enter with three lags and the other main variables enter with one or two lags, is estimated over 1970.4 -2000.4. We find however that an evaluation of steady-state properties gave meaningless results when the Johansen (1988) cointegration procedure is adopted and attempts to restrict the long run by plausible theory restrictions (confer the previous section) are overwhelmingly rejected.

There are several reasons for this outcome:

- One is that the labour input measure (total employment) is too crude and possibly in itself poorly measured, leading to serious measurement problems for the wage variables as well as the productivity measure. An alternative labour input measure - based on annual data for hours worked (see Appendix C.2 for a discussion) - was also adopted and the long run was reestimated for a shorter sample, 1980.4. - 2000.4, but failed to improve the results.

\footnotetext{
${ }^{14}$ It is conceivable that producers' prices may deviate much more from consumer prices at a sectoral level than at an aggregate level, where the difference is mainly due to indirect taxation which is already included an explanatory variable. For a theoretical discussion of the role of the wedge in the wage bargaining, see Rødseth (2000).

${ }^{15}$ These includes two impulse dummies for 1981.1 and 1984.2 from the wage equation and two differenced impulse dummies for 1982.1 and 1992.4 and a combined dummy for 1977.4 and 1978.1.
} 
- A second reason is that the Euro area level of aggregation may be inappropriate for identifying labour market behaviour: The Euro area labour market is an aggregate of national labour markets, which is the level at which bargaining process takes place. It is known that the institutional arrangements - the degree centralisation and political involvement in the wage formation - vary across the Euro area countries. Hence, different events may have influenced the wage formation in different countries, see Barrell and Dury (2003) for a discussion.

In order to circumvent these difficulties we have chosen to use unit labour cost as our wage input in the following, which implies that wages and productivity is amalgamated into one variable, which is the ratio between the two. It follows that the variables that contain the long run real wage claims equations now are collected in the vector $\left[\begin{array}{llll}p & u l c & p i & u\end{array}\right]$. All other variables enter as described above and this system, where all main variables enter with three lags, is estimated over 1970.4-2000.4. The residual standard errors (in percent and denoted $\hat{\sigma}$ ) of each equation are shown in Table 1, together with the following three residual diagnostic tests: the F-form of the Lagrange multiplier test of autocorrelation of order 1 to 5 (denoted AR1-5), non-normality (Normality), and against heteroscedasticity, due to squares of the regressors (Heteroscedasticity). The square brackets contain p-values. There is no evidence of misspecification in the two equations that make up the unrestricted system. The three last rows show the system counterparts (indicated by the subscript $v$ ) of the three misspecification tests. All the empirical results in this paper are obtained with PcFiml 9.3 or PcGive 10 - see Doornik and Hendry (1997) and Hendry and Doornik (2001), respectively. Further details on the tests used are given in the references at the bottom of Table 2.

Again, the steady-state properties are evaluated using the Johansen (1988) cointegration procedure, after first establishing the presence of two cointegrating vectors. ${ }^{16}$

We impose restrictions on the steady state equations (14)-(15). As we argued above, since we are dealing with data for the aggregated level it is plausible that there is no wedge in the wage formation and normal cost pricing. We also find empirical support that indirect taxation is completely offset in long run inflation. Hence we end up with a restricted form of (14)-(15) where only $\varpi$ and $\phi$ are entered

\footnotetext{
${ }^{16}$ Using Table 3 in Harbo et al. (1998) for the case with three exogeneous variables $\left(u_{t}, p i_{t}, t_{t}\right)$, the 5 per cent critical values for rejecting zero and at most one cointegrating vector, are 35.4 and 17.8, respectively. The Trace-statistics of 51.88 and 21.48 (degrees of freedom corrected) give formal support to 2 cointegrating vectors.

If $u_{t}$ is considered as a stationary variable, the number of nonstationary exogenous variables are reduced to two, which lowers the 5 per cent critical values (of the rank test above) to 30.0 and 15.1 (degrees of freedom corrected) and hence this does not change our conclusion that $\mathrm{r}=2$. On the other hand it is known that the presence of a stationary unemployment variable implies that the critical values used for inference in this case are approximate, see Rahbek and Mosconi (1999)
} 
unrestrictedly:

$$
\begin{aligned}
u l c & =p-\varpi u, \\
p & =(1-\phi) u l c+\phi p i+t,
\end{aligned}
$$

with estimation results in Table 1

\begin{tabular}{|c|c|c|c|}
\hline \multicolumn{4}{|c|}{$\begin{array}{l}\text { The estimated steady state equations }(16)-(17) \\
\qquad u l c=p-\underset{(0.02)}{0.11 u} \\
\qquad p=0.91 \text { ulc }+\underset{(0.03)}{0.09} p i+t\end{array}$} \\
\hline $\begin{array}{r}\text { Cointegrated system } \\
52 \text { parameters } \\
\text { Normality } \chi^{2}(2) \\
\text { ARCH1-4 test } F(4,87) \\
\text { Heteroscedasticity } F(18,55) \\
\text { Overidentification } \chi^{2}(4) \\
\text { Normality }_{v} \chi^{2}(4) \\
\text { Heteroscedasticity }_{v} F(54,158) \\
\end{array}$ & $\begin{array}{c}u l c_{t} \\
4.56[0.10] \\
0.72[0.58] \\
0.90[0.59]\end{array}$ & $\begin{array}{c}p_{t} \\
4.33[0.11] \\
1.55[0.19] \\
1.03[0.44]\end{array}$ & $\begin{array}{l}8.25[0.08] \\
9.05[0.06] \\
0.98[0.51]\end{array}$ \\
\hline \multicolumn{4}{|c|}{$\begin{array}{c}\text { The sample is } 1970.4 \text { to } 2000.4,121 \text { observations. } \\
\end{array}$} \\
\hline \multicolumn{3}{|c|}{\begin{tabular}{c|} 
References: See Table 2. \\
\end{tabular}} & \\
\hline \multicolumn{3}{|c|}{ The numbers in [..] are p-values. } & \\
\hline
\end{tabular}

Table 1: The estimated steady-state equations .

The result for the markup equation is remarkably close to the (implicit) equilibrium correcting term for $\Delta p$ in AWM, cf equation (1), noting the difference between trend unit labour costs and actual unit labour costs. Figure 2 records the stability over the period 1991.1-2000.4 of the coefficient estimates in Table 1 with \pm 2 standard errors. The first equation says that in steady state labour's share of output is a function of unemployment, which a common finding in the literature see e.g. Bårdsen and Fisher (1999), Mizon (1995), and Marcellino and Mizon (2001) - but it is at odds with the AWM where the wage share equilibrium corrects to the unemployment's deviation from a NAIRU, see equation (25) of Appendix B. The estimated unit labour cost responsiveness to the rate of unemployment is approximately 0.1, which is close to the finding of Bårdsen et al. (2003) for the wage responsiveness to unemployment for Norway. We note the break in the level of this coefficient occurring in 1999.1 and onwards. 

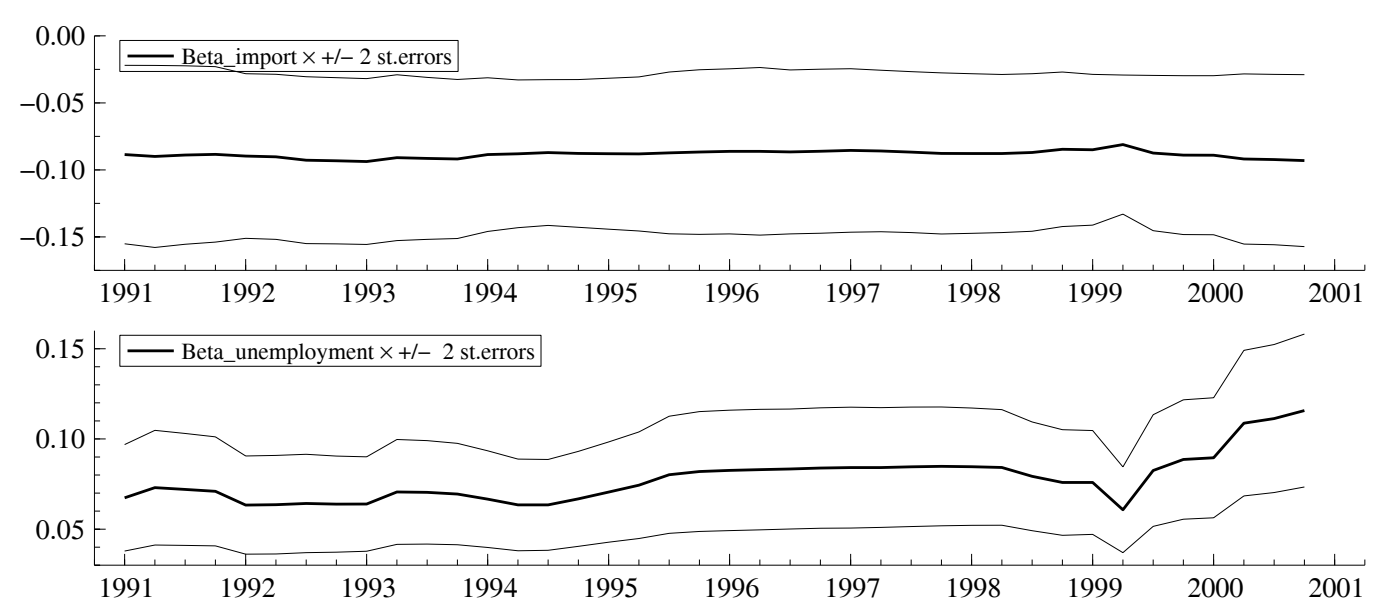

Figure 2: Identified cointegration vectors. Recursively estimated parameters (the elasticity of the import price in the price equation in the upper graph and the elasticity of unemployment in the wage equation below).

\subsection{The dynamic price - unit labour cost model}

When modelling the short run relationships we impose the estimated steady state from Table 1 , on a subsystem for $\left\{\Delta p_{t}, \Delta u l c_{t}\right\}$ conditional on $\left\{\Delta p i_{t}, \Delta u_{t-1}, \Delta t_{t}\right.$, $\left.\Delta p r_{t}\right\}$ with all variables entering with two additional lags. ${ }^{17}$ In addition to gap $_{t-1}$, we also augment the system with the dummies to capture short-run effects and also centred seasonals to capture whatever seasonal effects that are left in the seasonally adjusted data. The diagnostics of the unrestricted $\mathrm{I}(0)$ system are reported in the upper part of Table 2 .

The short run model is derived general to specific by deleting insignificant terms, establishing a parsimonious statistical representation of the data in $I(0)$ space, following Hendry and Mizon (1993). The resulting model is found below

$$
\begin{aligned}
& \widehat{\Delta p_{t}}=\underset{(0.003)}{0.031}+\underset{(0.04)}{0.36} \Delta u l c_{t}+\underset{(0.04)}{0.20} \Delta p_{t-2}-\underset{(0.04)}{0.013} \Delta p r_{t}+\underset{(0.01)}{0.10} \Delta p i_{t} \\
& +\underset{(0.13)}{0.24} \Delta t_{t-1}-\underset{(0.006)}{0.055}\left(p_{t-1}-0.908 u l c_{t-1}-0.092 p i_{t-1}\right)+\text { dummies } \\
& \sigma=0.0020
\end{aligned}
$$

\footnotetext{
${ }^{17}$ Despite the measurement problems mentioned in the previous section we include the change in productivity $\Delta p r_{t}$ in the the short run analysis, relying on changes to be more accurately measured than levels.
} 


$$
\begin{aligned}
\widehat{\Delta u l c_{t}}= & \underset{(0.006)}{-0.046}+\underset{(0.13)}{1.01} \Delta p_{t}+\underset{(0.11)}{0.27} \Delta p_{t-1}-\underset{(0.08)}{0.42} \Delta p r_{t}-\underset{(0.02)}{0.12} \Delta p i_{t} \\
& +\underset{(0.03)}{0.11} \mathrm{gap}_{t-1}-\underset{(0.007)}{0.047}\left(u l c_{t-1}-p_{t-1}-0.107 u_{t-1}\right)+\text { dummies } \\
& \sigma=0.0044
\end{aligned}
$$

The sample is 1971(1) to 2000(4), 120 observations.

The lower part of Table 2 contains diagnostics for the final model. Whilst single equation diagnostics indicate that there are autocorrelation in both equations, there is no autocorrelation in the system. Moreover, we observe the insignificance of Overidentification $\chi^{2}(36)$, which shows that the model reduction restrictions are supported by the data.

\begin{tabular}{|c|c|}
\hline \multicolumn{2}{|l|}{$\begin{array}{c}\text { Unrestricted } I(0) \text { system } \\
56 \text { parameters }\end{array}$} \\
\hline$\widehat{\sigma}_{\Delta p}$ & 0.0017 \\
\hline$\widehat{\sigma}_{\Delta u l c}$ & 0.0044 \\
\hline$A R_{v} 1-5 F(20,162)$ & $1.21[0.25]$ \\
\hline Normality $_{v} \chi^{2}(4)$ & $7.41[0.12]$ \\
\hline Heteroscedasticity $F(153,114)$ & $0.65[0.99]$ \\
\hline \multirow{2}{*}{\multicolumn{2}{|c|}{$\begin{array}{l}\text { Final Model } \\
20 \text { parameters }\end{array}$}} \\
\hline & \\
\hline \multicolumn{2}{|l|}{$\widehat{\sigma}_{\Delta n}$} \\
\hline \multicolumn{2}{|r|}{0.0044} \\
\hline \multicolumn{2}{|l|}{ Overidentification $\chi^{2}(36)$} \\
\hline $\begin{array}{r}\text { Uveriaentification } \chi \\
\qquad A R_{v} 1-5 F(20,198)\end{array}$ & $0.95[0.53]$ \\
\hline \multicolumn{2}{|l|}{$\begin{array}{r}A R_{v} 1-5 \quad F(20,198) \\
\text { Normality }_{v} \chi^{2}(4)\end{array}$} \\
\hline \multicolumn{2}{|c|}{ Heteroscedasticity ${ }_{v} F(108,213) \quad 0.76[0.97]$} \\
\hline \multicolumn{2}{|c|}{ The sample is $1971(1)$ to $2000(4), 120$ observations. } \\
\hline \multicolumn{2}{|c|}{$\begin{array}{c}\text { References: Overidentification test (Anderson and Rubin (1949, 1950), } \\
\text { Koopmans et al. (1950), Sargan (1988)), } \\
\text { AR-test (Godfrey (1978) and Doornik (1996)), } \\
\text { Normality test (Doornik and Hansen (1994)), and } \\
\text { Heteroscedasticity test (White (1980) and Doornik (1996)). }\end{array}$} \\
\hline \multicolumn{2}{|c|}{ "The numbers in [..] are p-values. } \\
\hline
\end{tabular}

Table 2: Diagnostics for the unrestricted and restricted (parsimonious) I(0) price unit labour cost system and the model.

In the first equation (18) the rate of inflation is determined by changes in unit labour costs and import prices and there are significant short term effects of changes in productivity (negative) and changes in indirect taxes (positive). Output gap is not significant in the inflation equation but works through unit labour cost which 

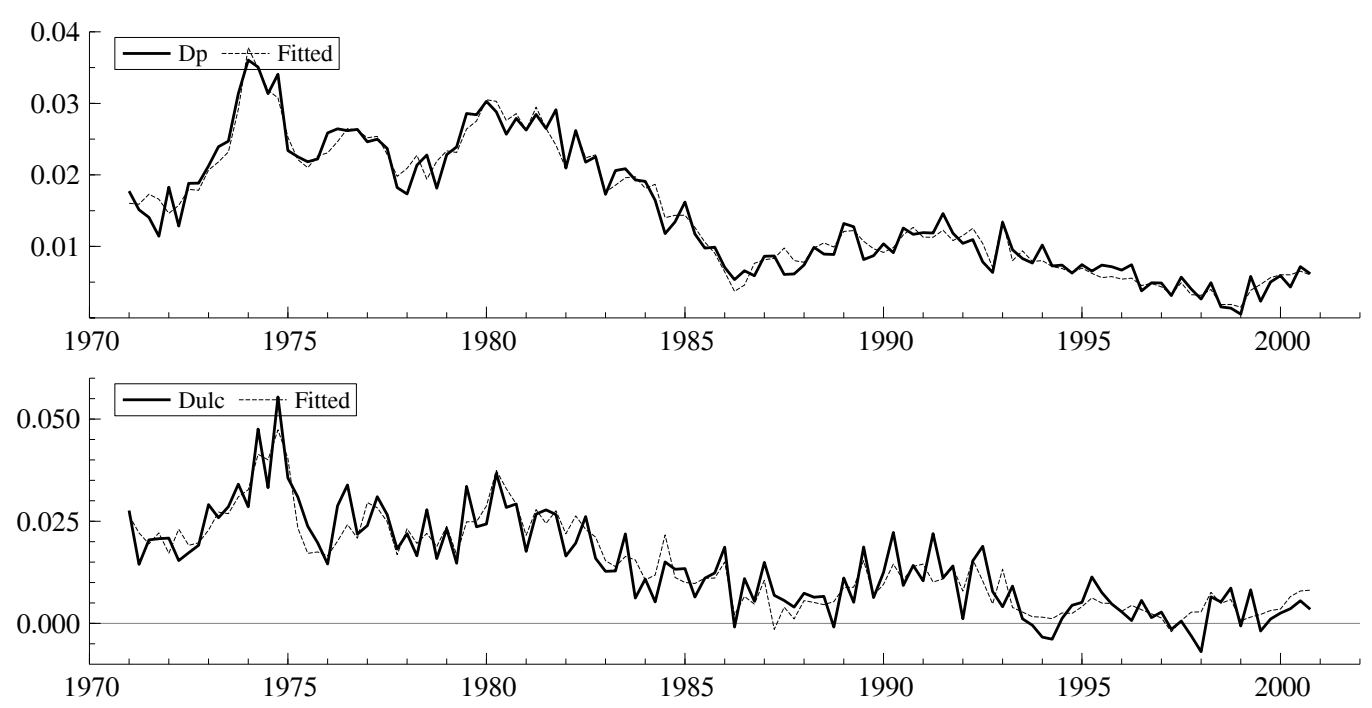

Figure 3: Actual and fitted values of quarterly price and unit labour cost inflation.

has the expected positive sign. If we consider the two price equations ((26) and (27) in Appendix B) of AWM together, we find that similar factors determine inflation there. Moreover, we find an additional short run effect of the world prices of raw materials and trend unit labour cost substitutes for unit labour cost both in the short run and the long run.

The unit coefficient on the rate of inflation in the second equation implies that the equation can be interpreted as explaining the change in the wage share, another similarity to the AWM model, see Appendix B. The equilibrium-correction terms are highly significant in both equations, (18) and (19), which is consistent with cointegration.

As discussed by Kolsrud and Nymoen (1998), the question whether systems like ours have a NAIRU property hinges on the detailed restrictions on the short run dynamics. They show that two necessary conditions for the NAIRU property are that wage growth is homogenous with respect to $\Delta q_{t}$ and - at the same time - the price equation is homogenous with respect to the wage growth. These implications carry over to our model with $\Delta u l c_{t}$ substituted for wage growth. From the price equation it is easily seen that short run homogeneity is far from fulfilled, and this implies that we do not have a NAIRU model. ${ }^{18}$

From the steady state of (19) we have that the long run unemployment elasticity of unit labour cost, -0.10 , is large enough to represent a channel for economic policy on inflation, which runs contrary to the assumed NAIRU of AWM.

\footnotetext{
${ }^{18}$ For the unit labour cost growth equation (19) on the other hand we find the implied unit labour cost elasticities with respect to $\Delta q_{t}$ and $\Delta p i_{t}$ are 1.15 and 0.005 , respectively, which are not significantly different from 1 and 0 . (Using $\Delta p_{t} \equiv(1-\phi) \Delta q_{t}+\phi \Delta p i_{t}$, the maintained value of $\phi=0.09$ from Table 1 and observing that $\Delta p i_{t}$ is significant in the unit labour cost equation).
} 

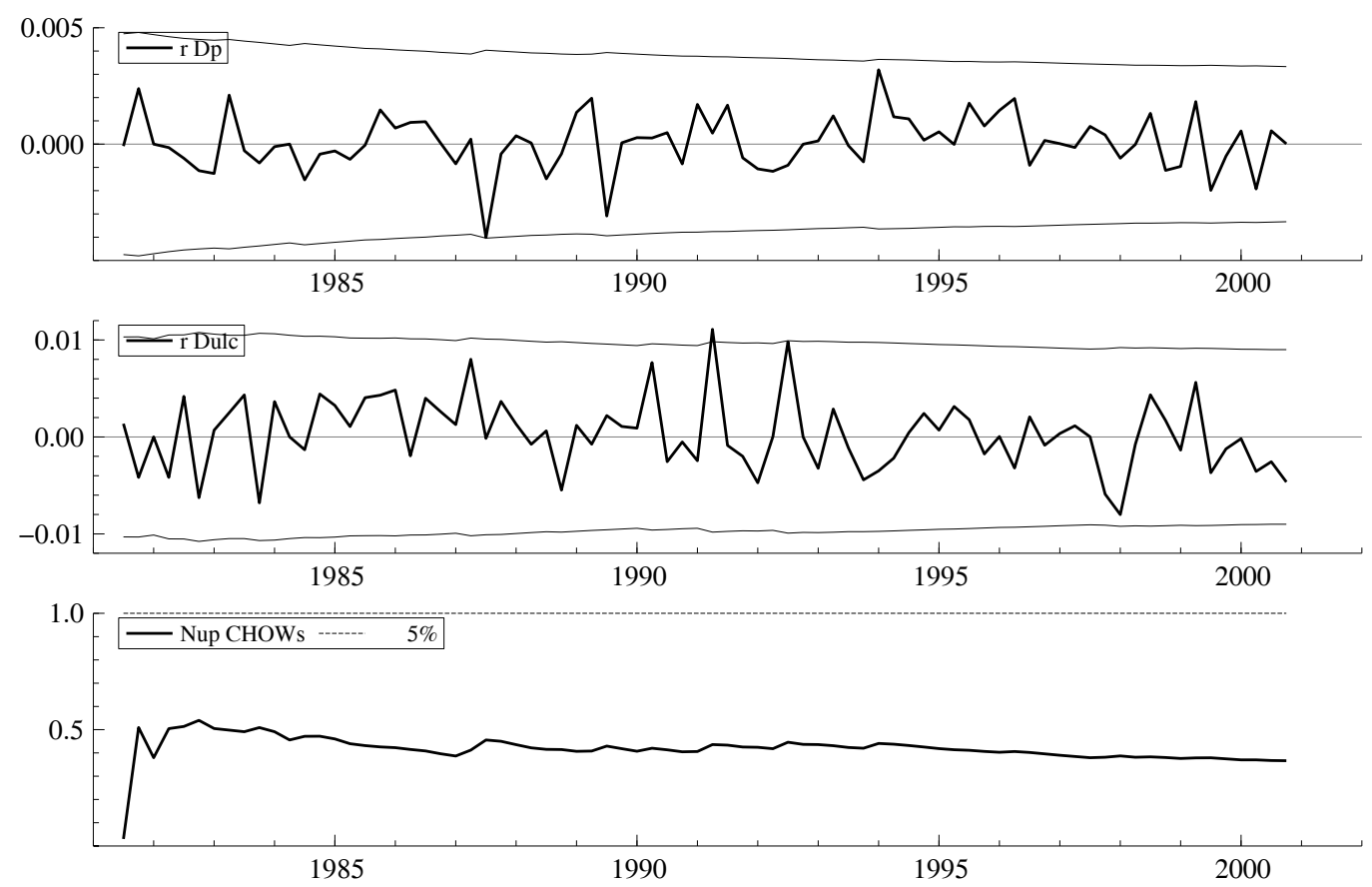

Figure 4: Recursive stability tests for the model. The upper two panels show recursive residuals for the model. The lower panel shows recursive Chow-tests (right).

\subsection{Valid conditioning}

In terms of the sketch in Figure 1, weak exogeneity ${ }^{19}$ of the conditioning variables for the parameters of the wage-price model $D_{\mathbf{y}}\left(\mathbf{y}_{t} \mid \mathbf{z}_{t}, \mathbf{Y}_{t-1}, \mathbf{Z}_{t-1}\right)$ implies that these parameters are free to vary with respect to the parameters of the marginal models for the output gap $\left(\right.$ gap $\left._{t}\right)$, the nominal exchange rate $\left(e_{t}^{n o m}\right)$, which works through $p i_{t}$, and unemployment $\left(u_{t}\right)$, i.e. $D_{\mathbf{z}_{1}}\left(\mathbf{z}_{1 t} \mid \mathbf{z}_{2 t}, \mathbf{z}_{3 t}, \mathbf{Y}_{t-1}, \mathbf{Z}_{t-1}\right)$. Below we follow Johansen (1992) and concentrate the testing to the parameters of the cointegration vectors of the price - unit labour cost model.

We have established three simple marginal models: The estimated equations for the output gap and the exchange rate are autoregressions and unemployment is in addition regressed on lags in output growth. ${ }^{20}$ We have tested for weak exogeneity of the three conditioning variables with respect to the long run parameters by testing the significance of the two cointegrating terms from Table 1 when we include them in the marginal equations. The results of Wald-test of the joint significance of the two steady state terms are reported in Table 3 and they support weak exogeneity.

\footnotetext{
${ }^{19}$ See Engle et al. (1983) for a definition.

${ }^{20}$ Whereas the autoregressions (including a lagged levels term) for output gap and the nominal exchange rate appear to be congruent, albeit with a low $R^{2}$, the unemployment equation reveals signs of misspecification, suggesting a need for respecification.
} 
Table 3: Testing weak exogeneity

\begin{tabular}{|l|l|}
\hline & ecmulc $_{t}^{I C M} \& e c m p_{t}^{I C M}$ \\
\hline$\Delta e_{t}^{\text {nom }}$ & $\chi^{2}(2)=1.26[0.53]$ \\
\hline$\Delta$ gap $_{t}$ & $\chi^{2}(2)=0.73[0.69]$ \\
\hline$\Delta u_{t}$ & $\chi^{2}(2)=2.87[0.24]$ \\
\hline
\end{tabular}

\section{The models - evaluation and forecast comparisons}

In this section we present estimated reduced form versions of the AWM and ICM inflation equations in order to evaluate the models and to compare forecasts based on these equations with forecasts from the two single equation inflation models we discussed in Section 2.2, i.e. the $\mathrm{P}^{*}$-model and the New Keynesian Phillips curve. The models are estimated on a common sample covering $1972.4-2000.3$, and they are presented in turn below, whereas data sources and variable definitions are found in Appendix C.

\subsection{The reduced form AWM inflation equation}

We establish the reduced form inflation equation from the Area Wide Model by combining the two price equation (26) and (27) of Appendix B. The reduced form equation is modelled general to specific: We start out with a fairly general information set which includes the variables of the wage price block of the AWM: three lags of inflation, $\Delta p$, as well as of changes in trend unit labour costs, $\Delta \overline{u l c}$, and two lags of the changes in: the wage share, $\Delta w s$, the world commodity price index, $\Delta p^{\text {raw }}$, the gdp deflator at factor prices, $\Delta q$, unemployment, $\Delta u$, productivity, $\Delta p r$, import prices, $\Delta p i$, and indirect taxes, $\Delta t$. The output gap is included with lagged level $\left(g a p_{t-1}\right)$ and change $\left(\Delta g a p_{t-1}\right)$. The dummies from the wage and price block of AWM, $\Delta I 82.1, \Delta I 82.1, I 92.4, I 77.4 I 78.1, I 81.1$, and $\Delta I 84.2^{21}$, are included and a set of centred seasonal dummies (to mop up remaining seasonality in the data, if any). Finally, we include into the reduced form information set two equilibrium correction terms: the combined term from (26) and (27) in equation (1), ecmp $p_{t}^{A W M}$, and the equilibrium correction term, $e c m w_{t}^{A W M}$, from the wage share equation (25).

The parsimonious reduced form AWM inflation equation becomes:

\footnotetext{
${ }^{21}$ The first three are significant in all estimated equations reported below, the last two which originate in the AWM wage equation are always insignificant.
} 


$$
\begin{aligned}
& \widehat{\Delta p_{t}}=\underset{(0.017)}{0.077}+\underset{(0.06)}{0.19} \Delta p_{t-3}+\underset{(0.05)}{0.08} \Delta \overline{u l c}_{t-1}+\underset{(0.08)}{0.34} \Delta q_{t-1} \\
& -\underset{(0.04)}{0.07} \Delta p r_{t-2}+\underset{(0.01)}{0.07} \Delta p i_{t-1}+\underset{(0.28)}{0.82} \Delta t_{t-1} \\
& -\underset{(0.011)}{0.051 e c m p} p_{t-1}^{A W M}-\underset{(0.0015)}{0.01} e c m w_{t-1}^{A W M}+\text { dummies } \\
& \sigma=0.00188 \quad 1972.4-2000.3 \\
& F_{A R 1-5}(5,94)=0.41[0.84] \quad F_{A R C H 1-4}(4,91)=0.43[0.78] \\
& \text { Normality test } \chi^{2}(2)=1.01[0.60] \quad F_{\text {HETERO }}(23,75)=1.35[0.17] \\
& F_{R E S E T}(1,98)=0.06[0.80]
\end{aligned}
$$

All restrictions imposed on the general model leading to (20), are accepted by the data, both sequentially and when tested together. We note that the effects of the explanatory variables are much in the line with the structural equations reported in Appendix B and that both equilibrium correction terms are highly significant. The fit is poorer than for the structural inflation equation, which is mainly due to the exclusion of contemporary variables in the reduced form. If we include contemporary $\Delta p i, \Delta p r$, and $\Delta p^{r a w}$, the standard error of the equation improves by $30 \%$ and a value close to the estimated $\sigma$ of equation (27) obtains. Figure 5 contains recursive estimates of the model's coefficients. We note that there is a slight instability in the adjustment speed for the two equilibrium terms in the period 1994-1996.
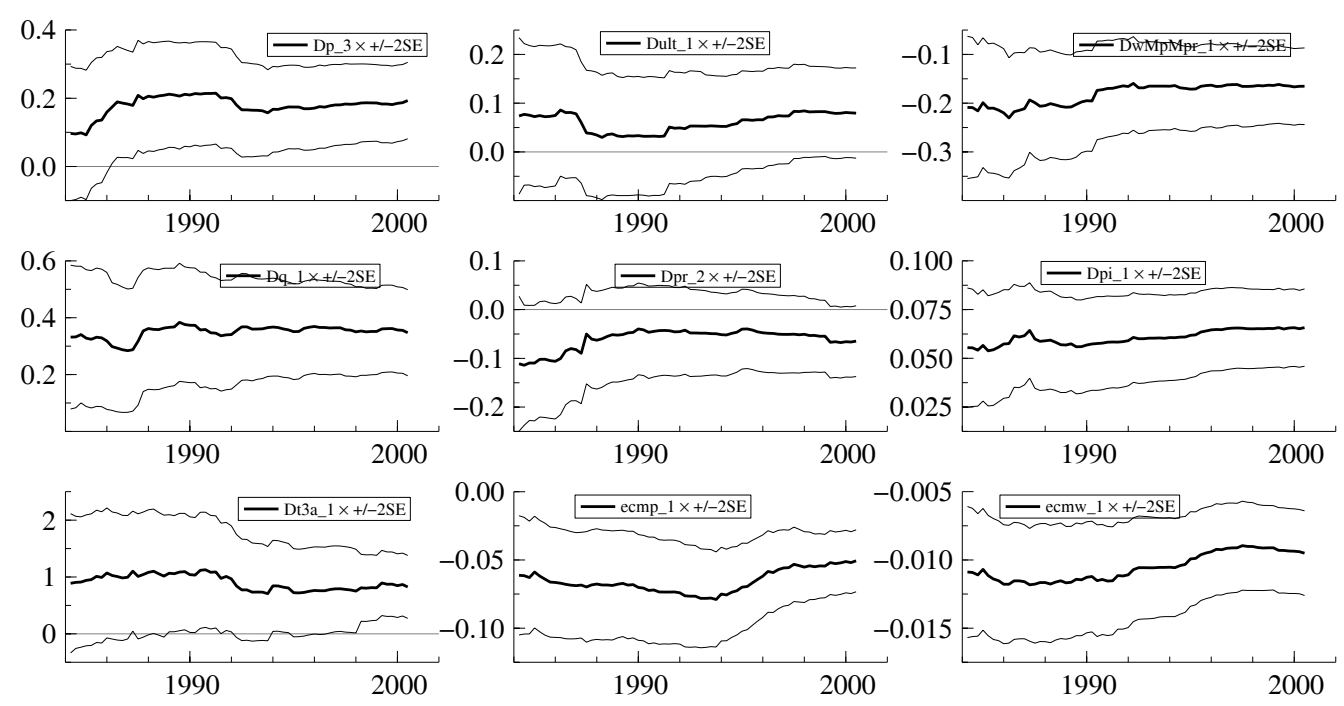

Figure 5: Recursive estimates for the coefficients of the (reduced form) AWM inflation equation.

\subsection{The reduced form ICM inflation equation}

We derive a reduced form inflation equation for the incomplete competition model (ICM) much in the same vein as for the AWM. The information set for this model 
is given by all variables included in the price - unit labour cost system of Section 3.4. The information set differs from that of the AWM on the following points: lags of changes in unit labour costs, ulc, are used instead of lags of changes in trend unit labour costs; the changes in the wage share, $\Delta w s$, the world commodity price index, $\Delta p^{r a w}$, and the gdp deflator at factor prices, $\Delta q$, are not included; and the equilibrium corrections terms are those of the ICM model, ecmp $p_{t}^{I C M}$ and $e c m u l c_{t}^{I C M}$, as reported in Table 1.

After imposing valid restrictions on the general model, the final reduced form ICM inflation equation becomes:

$$
\begin{aligned}
& \widehat{\Delta p_{t}}=\underset{(0.006)}{0.014}+\underset{(0.10)}{0.41} \Delta p_{t-1}+\underset{(0.08)}{0.16} \Delta p_{t-2}+\underset{(0.01)}{0.03} \Delta p i_{t-1} \\
& +\underset{(0.02)}{0.06} \operatorname{gap}_{t-1}+\underset{(0.04)}{0.14} \Delta \operatorname{gap}_{t-1} \\
& -\underset{(0.016)}{0.078} e^{0 c m p} p_{t-1}^{I C M}-\underset{(0.007)}{0.031} \text { ecmul }_{t-1}^{I C M}+\text { dummies } \\
& \sigma=0.00205 \\
& 1972.4-2000.3 \\
& F_{A R 1-5}(5,96)=0.62[0.68] \\
& F_{A R C H 1-4}(4,93)=0.18[0.95] \\
& \text { Normality test } \chi^{2}(2)=0.16[0.92] \quad F_{\text {HETERO }}(20,80)=0.64[0.87] \\
& F_{R E S E T}(1,100)=2.98[0.09]
\end{aligned}
$$

We observe that the reduced form inflation equation of the ICM is variance encompassed by the corresponding AWM equation. Again, all restriction imposed on the general model to obtain (21) are accepted by the data, both sequentially and when tested together. The reduced form inflation equation picks up the combined effects from the price and the unit labour cost structural equations, the latter is seen through the significant effects of $\Delta p_{t-1}, g a p_{t-1}$ and the equilibrium correction term ecmulc $c_{t}^{I C M}$ in (21). Figure 6 contains recursive estimates of the coefficients in (21). We note that the speed of adjustment towards the steady state for the two error corrections terms are more stable than in the case of AWM. 

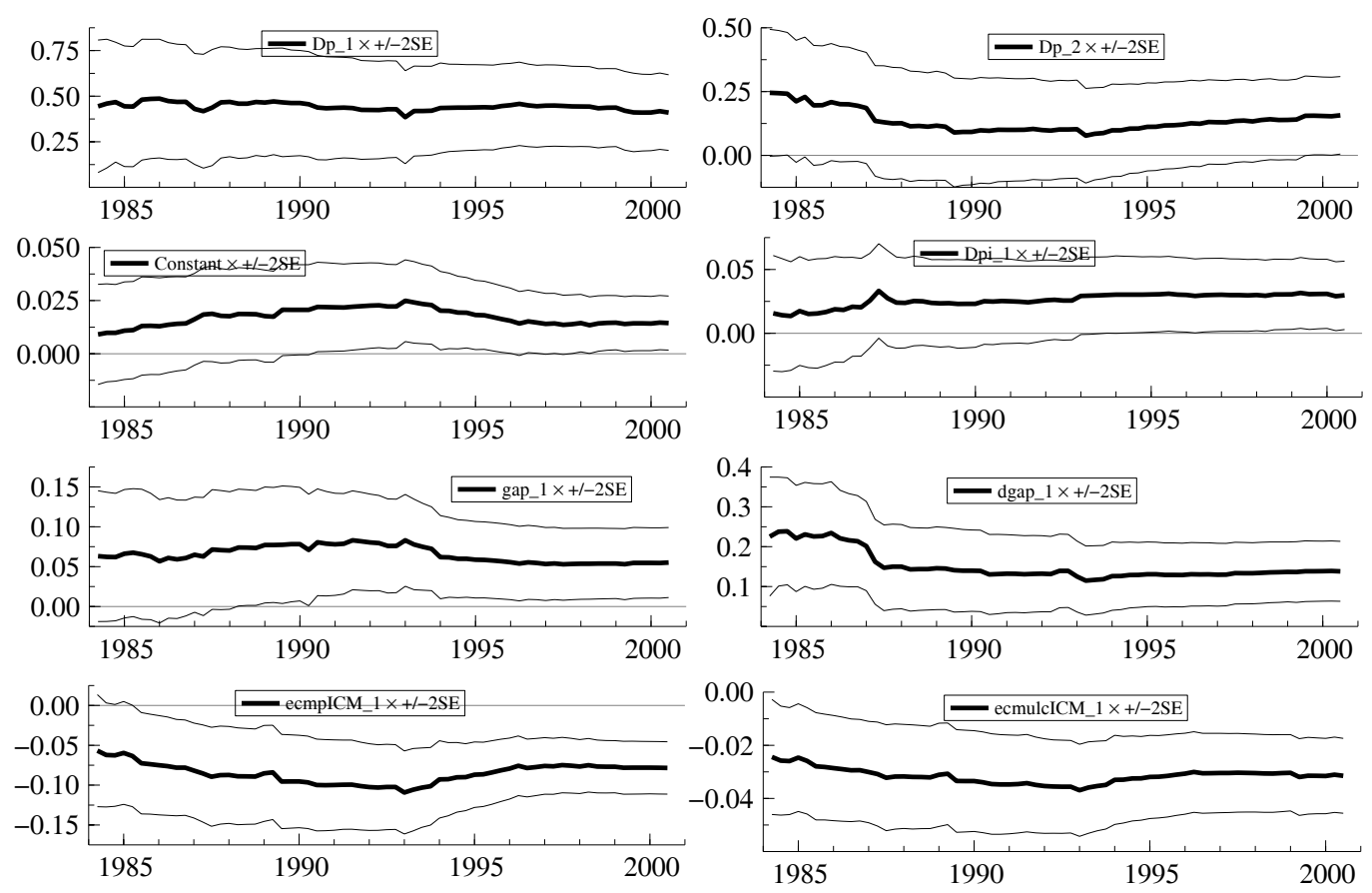

Figure 6: Recursive coefficient estimates of the reduced form ICM.

\subsection{The $\mathrm{P}^{*}$ model}

The $\mathrm{P}^{*}$ model is estimated in two versions: One version is related to the standard formulation of $\mathrm{P}^{*}$-model as discussed in Section 2.2, in which inflation is explained by the real money gap $\left(r m-r m^{*}\right)$ and the differences between actual price and money growth from their reference (target) paths, $\Delta_{4}$ pgap and $\Delta_{4}$ mgap ${ }^{22}$. In order to retaining comparability across the inflation models, we differ from previous studies by using the private consumption deflator rather than e.g. the gdp deflator of Trecroci and Vega (2002) or a consumer prices index like the one constructed by Gerlach and Svensson (2003). We have also included four lags of inflation, two lags of output growth, $\Delta y$, and an interest rate spread gap sgap (defined as the deviations of the actual spread from a Hodrick Prescott trend spread). The other version, $\mathrm{P}^{*}$ enhanced, is modelled general to specific, where the general specification is based the information set of AWM with $\left(r m-r m^{*}\right), \Delta_{4} p g a p, \Delta_{4}$ mgap and sgap substituted for the equilibrium correction terms ecmp $p_{t}^{A W M}$ and $e c m w_{t}^{A W M}$.

After we have imposed valid restrictions, the first version based on the narrower information set becomes:

\footnotetext{
${ }^{22}$ We have considered two alternative reference paths for inflation: it is either trend inflation from a smoothed Hodrick-Prescott filter, or the same series with the reference path for the price (target) variable of Gerlach and Svensson (2003) substituted in for the period 1985.1 - 2000.2, see Appendix C.3. It is seen that the alternative reference path series share a common pattern. Here we report results based on the first alternative.
} 


$$
\begin{aligned}
& \widehat{\Delta p_{t}}=-\underset{(0.0005)}{0.0015}+\underset{(0.08)}{0.60} \Delta p_{t-1}+\underset{(0.09)}{0.24} \Delta p_{t-2}+\underset{(0.07)}{0.19} \Delta p_{t-4} \\
& +\underset{(0.04)}{0.18} \Delta y_{t-1}-\underset{(0.02)}{0.05} \Delta_{4} \text { pgap }_{t-1}-\underset{(0.03)}{0.04} \Delta_{4} m_{g a p} p_{t-1} \\
& \underset{(0.03)}{0.08}\left(r m-r m^{*}\right)_{t-1}-\underset{(0.0003)}{0.0006} \operatorname{sgap}_{t-1}+\text { dummies } \\
& \sigma=0.00211 \quad 1972.4-2000.3 \\
& F_{A R 1-5}(5,95)=0.52[0.76] \quad F_{A R C H 1-4}(4,92)=0.68[0.61] \\
& \text { Normality test } \chi^{2}(2)=0.42[0.81] \quad F_{\text {HETERO }}(21,78)=0.81[0.70] \\
& F_{R E S E T}(1,99)=7.27\left[0.008^{* *}\right]
\end{aligned}
$$

We find that money growth deviation from target $\Delta_{4} m g a p_{t-1}$ is insignificant which is in line with results reported in Gerlach and Svensson (2003). The other explanatory variables specific to the $\mathrm{P}^{*}$ model comes out significant and with expected signs. The model shows signs of misspecification through the significant RESET-test.

The enhanced $\mathrm{P}^{*}$ model - based on the broader information set - is given by:

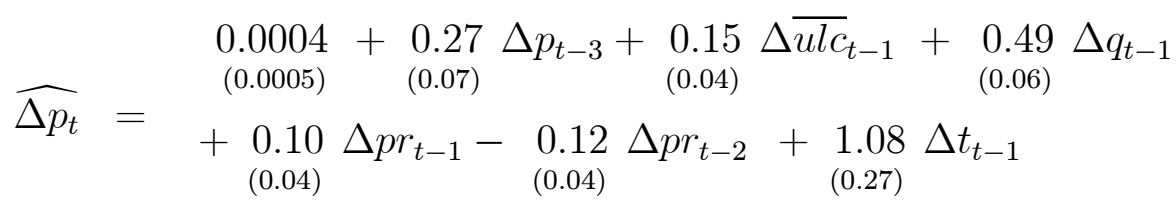

$$
\begin{aligned}
& -\underset{(0.02)}{0.03} \Delta_{4} \mathrm{pgap}_{t-1}-\underset{(0.025)}{0.04} \Delta_{4} \mathrm{mgap}_{t-1}+\underset{(0.02)}{0.11}\left(r m-r m^{*}\right)_{t-1}+\text { dummies } \\
& \sigma=0.00190 \\
& F_{A R 1-5}(5,93)=0.65[0.66] \\
& 1972.4-2000.3 \\
& \text { Normality test } \chi^{2}(2)=3.83[0.15] \quad F_{\text {HETERO }}(25,72)=0.76[0.77] \\
& F_{\text {RESET }}(1,97)=0.01[0.93]
\end{aligned}
$$

The model reduction is supported by the data, and the enhanced $\mathrm{P}^{*}$ is well specified according to the standard diagnostics reported. We find the $\mathrm{P}^{*}$-model based on the broader information set variance encompasses the $\mathrm{P}^{*}$-model derived from the narrower set of variables, with a reduction the estimated $\sigma$ of equation (23) of 10 per cent compared to the estimated $\sigma$ of equation (22).

A striking feature of the enhanced $\mathrm{P}^{*}$ model is that the short run explanatory variables in the first two lines are nearly identical to its counterpart in the AWM reduced form inflation equation $\left(\Delta p r_{t-1}\right.$ substituting for $\left.\Delta p i_{t-1}\right)$ with coefficients of the same order of magnitude. The real money gap $\left(r m-r m^{*}\right)$ is highly significant, whereas sgap drops out. Also, the $\mathrm{P}^{*}$ - specific explanatory variables, $\Delta_{4}$ pgap and $\Delta_{4}$ mgap - the deviations from target - are insignificant at the 5 per cent level, but are retained to represent the $\mathrm{P}^{*}$ mechanisms.

Figure 7 shows that the coefficient estimates of the enhanced $\mathrm{P}^{*}$-model are recursively stable. 

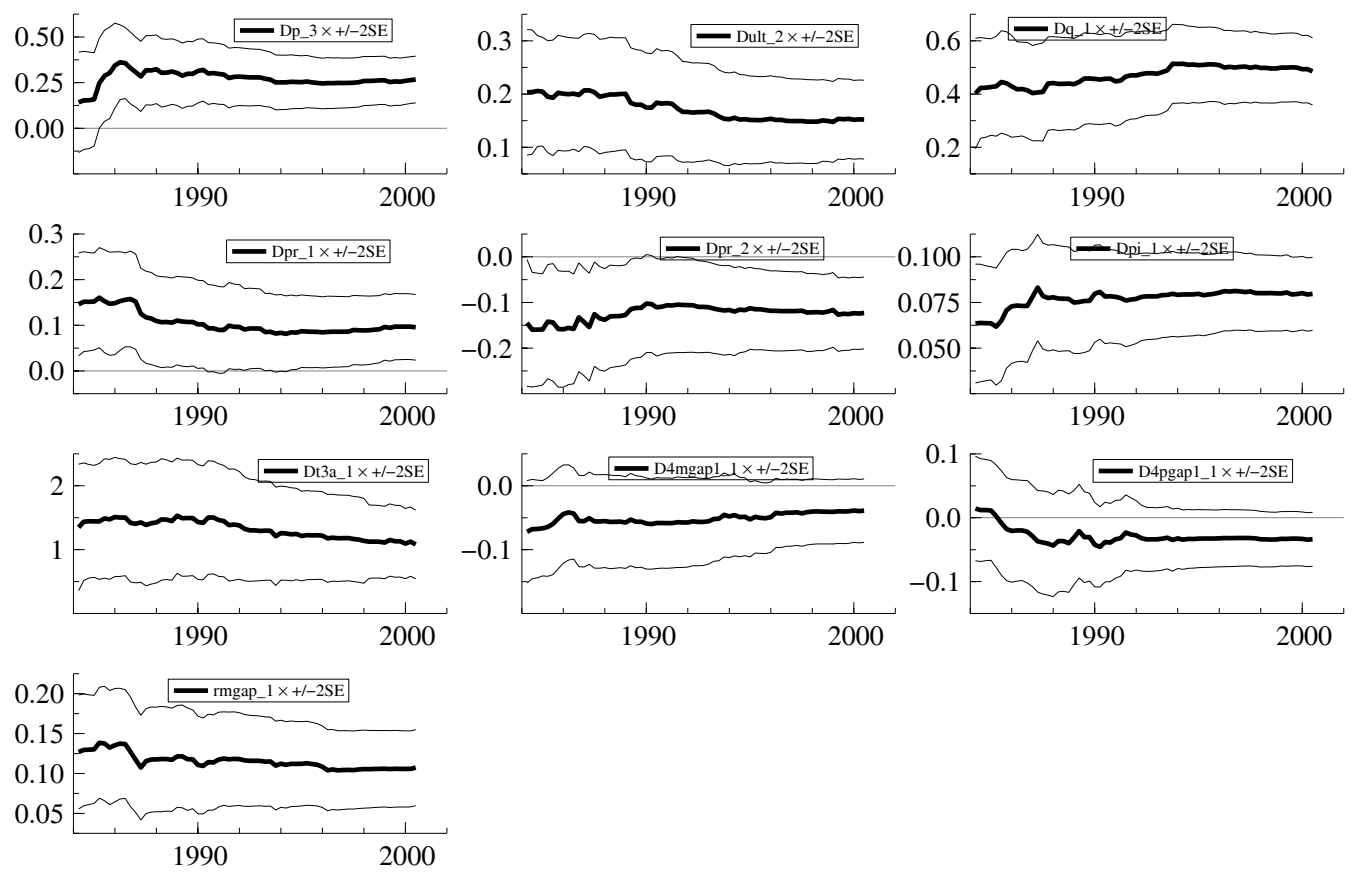

Figure 7: Recursive coefficient estimates of the $\mathrm{P}^{*}$-model based on the broad information set.

\subsection{The New Keynesian Phillips curve}

We have estimated a hybrid New Keynesian Phillips curve (NPC) as described in section 2.2. Using the instruments of Galí et al. (2001) ${ }^{23}$ - five lags of inflation, $\Delta p$, and two lags in the wage share, ws, and output gap, gap - we are able to replicate the results for the hybrid model in Bårdsen et al. (2004b), which in turn are representative for the empirical results reported in Galí et al. (2001). We have chosen to estimate a small simultaneous model where the inflation lead $\Delta p_{t+1}$ and the wage share $w s_{t}$ are specified as functions of the instruments and full information maximum likelihood estimation ${ }^{24}$ then yields the following inflation equation:

\footnotetext{
${ }^{23}$ Rudd and Whelan (2004) show that the inclusion of $\Delta p_{t-1}$ among the instruments leads to an upward bias in the estimates for the forward variable, see also Roberts (2001). We have however maintained the use of the Galí et al. (2001) instruments simply to get as close as possible to the estimation procedure adopted by the "proprietors" of the NPC model in the same way as we have tried to do in the cases of AWM price block and the $\mathrm{P}^{*}$ model above.

${ }^{24}$ Our estimation method thus differs from those in Bårdsen et al. (2004b), who estimate the hybrid model using Generalised Method of Moments (GMM) as well as estimation by two stage least squares. We note that Bårdsen et al. (2004b) like Galí et al. (2001) use the gdp deflator whilst we entertain the consumption deflator.
} 


$$
\begin{aligned}
& \widehat{\Delta p_{t}}=\underset{(0.006)}{0.0008}+\underset{(0.07)}{0.72} \Delta p_{t+1}+\underset{(0.07)}{0.31} \Delta p_{t-1}+\underset{(0.008)}{0.002} w s_{t}+\text { dummies } \\
& \sigma=0.00232 \quad 1972.4-2000.3 \\
& \text { Single equation diagnostics } \\
& F_{A R 1-5}(5,96)=4.55\left[0.001^{* *}\right] \quad F_{A R C H 1-4}(4,97)=0.87[0.48] \\
& \text { Normality test } \chi^{2}(2)=5.16[0.08] \quad F_{\text {HETERO }}(18,86)=1.56[0.09] \\
& A R_{v} 1-5 \quad F(45,262)=9.45\left[0.000^{* *}\right] \\
& \text { Normality }_{v} \chi^{2}(6)=8.64[0.19] \\
& \text { Heteroscedasticity } F(108,471)=1.38\left[0.01^{*}\right]
\end{aligned}
$$

In (24) we have augmented the NPC equation with the significant dummies from the other models. Increasing the information set by adding more instruments do not change the estimates for the NPC equation. The dummies reduce the estimated $\sigma$ for the the NPC by 10 per cent, but this is still 10-20 percent higher than the other three model classes. The highly significant $A R_{v} 1-5 F$-test in (24) is not only due to first order autocorrelation (which is consistent with the New Keynesian Phillips curve theor $\mathrm{y}^{25}$ ), but reflects also higher order autocorrelation. Figure 8 underscores that the coefficients of the forward and the backward terms of the NPC are recursively stable, as is also the wage share coefficient at a zero value.
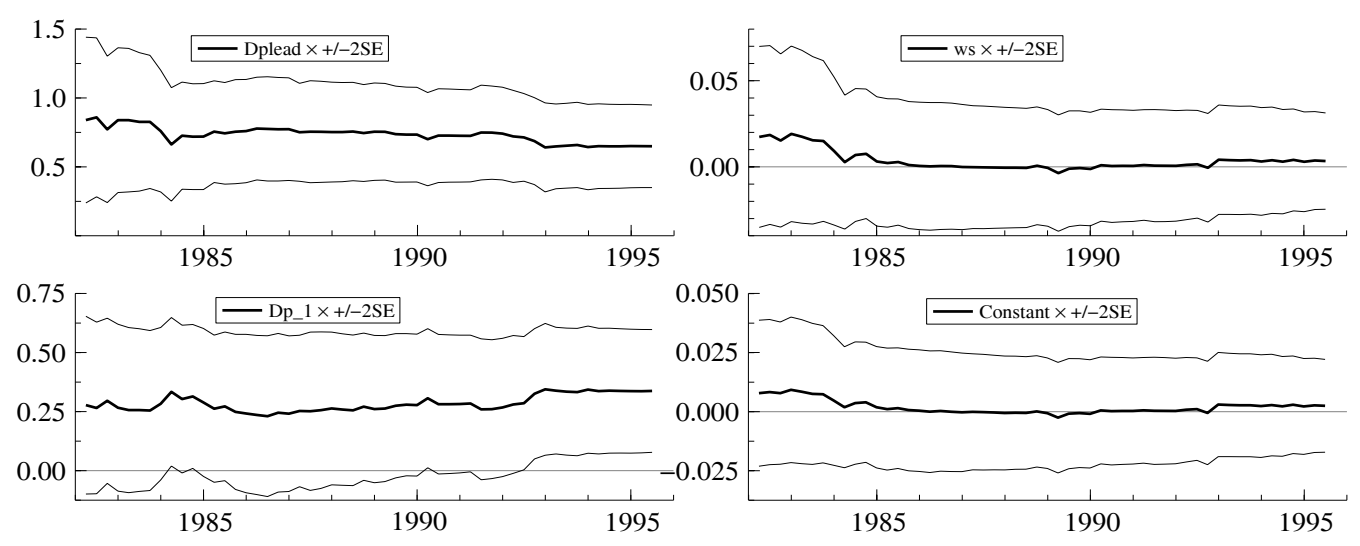

Figure 8: Recursive coefficient estimates of the hybrid New Keynesian Phillips curve (estimated by instrumental variables)

\footnotetext{
${ }^{25}$ First order autocorrelation may also have other causes, as pointed out by Bårdsen et al. (2002).
} 


\subsection{Evaluation of the inflation models' properties}

In this section ${ }^{26}$ we summarize the statistical properties of the different inflation models, in order to make more formal comparisons. In Table 4 we have collected the p-values for the misspecification tests for residual autocorrelation, autoregressive conditional heteroscedasticity, non-normality and wrong functional form. With the exception of the normality tests which are $\chi^{2}(2)$, we have reported F-versions of all tests, as in the previous sections.

Table 4: Misspecification tests

\begin{tabular}{||l|l|l||l|l|l|l|l||}
\hline$\Delta p$ model & $k$ & $\sigma_{\hat{\Delta} p} \%$ & $A R ~ 1-5$ & $A R C H ~ 1-5$ & Normality & Hetero & RESET \\
\hline & & & \multicolumn{5}{|c||}{ p-values } \\
\hline AWM & 13 & 0.19 & 0.84 & 0.78 & 0.60 & 0.17 & 0.80 \\
ICM & 11 & 0.21 & 0.68 & 0.95 & 0.92 & 0.87 & 0.09 \\
$\mathrm{P}^{*}$ & 12 & 0.21 & 0.76 & 0.61 & 0.81 & 0.70 & $0.008^{* *}$ \\
$\mathrm{P}^{*}$ enh & 14 & 0.19 & 0.66 & 0.56 & 0.15 & 0.77 & 0.93 \\
NPC & 7 & 0.23 & $0.00^{* *}$ & 0.48 & 0.08 & $0.01^{*}$ & \\
\hline \hline
\end{tabular}

One way of condensing this information is to perform encompassing tests ${ }^{27}$. In Table 5 we consider AWM as the incumbent model, the one we want to compare with its competitors, while ICM has this role in Table 6. In these tables, we show the p-values for two types of encompassing tests. In the case of the first table, the first statistic $-\mathrm{F}_{E n c, 1}$ - tests the AWM against each of the three alternatives ${ }^{28}$ using joint F-tests for parsimonious encompassing of each of the two models in question against their minimal nesting model. The second test, $\mathrm{F}_{E n c, 2}$, is based on pairs of model residuals from the AWM $\left(M_{1}\right)$ and from each of the alternative inflation models $M_{j}$. In each case we regress $\hat{\varepsilon}_{1, t}$, against the difference between the residuals of model $j$ and model 1 respectively, $\hat{\varepsilon}_{j t}-\hat{\varepsilon}_{1 t}$. Under the null hypothesis that model $M_{1}$, the AWM, encompasses model $M_{j}$, the coefficient of this difference has zero expectation. The hypothesis that model $M_{j}$ encompasses $M_{1}$ is tested by running the regression of the residuals from model $M_{j}, \hat{\varepsilon}_{j, t}$, on the same difference (with changed sign). The simple F-test of the hypothesis that the difference has no (linear) effect is reported in the table. Following Mizon and Richard (1986) and Hendry and Richard (1989), a congruent encompassing model can account for the results obtained by rival models, and hence encompassing tests form a richer basis for model comparison than ordinary goodness-of-fit measures.

Table 5 and Table 6 show results from the two encompassing tests explained above, and in addition we report a test for parsimonious encompassing. We have embraced all five models in forming their minimal nesting model, and report pvalues of $\mathrm{F}_{\text {EncGum }}$ tests in the fourth column of the two tables. ${ }^{29}$ We see that only

\footnotetext{
${ }^{26}$ This section and the next (Section 4.6) draw on Eitrheim and Jansen (2003)

${ }^{27}$ For an introduction to encompassing principle, see Mizon and Richard (1986) and Hendry and Richard (1989)

${ }^{28}$ For technical reasons the NPC was not included in these tests.

${ }^{29}$ It should be noted that the encompassing tests $\mathrm{F}_{\text {EncGum }}$, reported in Tables 5 and 6 , are based on two stage least squares estimation of the NPC. This gives estimates of the inflation equation that are close to, but not identical to, those in equation (24), since FIML takes account of the covariance structure of the system. In order to form the minimal nesting model it was necessary
} 
the AWM parsimoniously encompasses the General Unrestricted Model $\left(\mathrm{GUM}^{30}\right)$. For all the other models we obtain outright rejection of the corresponding set of restrictions relative to the GUM. In some cases the pair of models seem to mutually encompass each other. When both tests are mutually rejected this is prima facie evidence that both models are misspecified, see Ericsson (1992).

Table 5: Encompassing tests with AWM as incumbent model

\begin{tabular}{||l|l|l|l|l||l|l||l|l||}
\hline$\Delta p$ model & $k$ & $\sigma_{\hat{\Delta}} \%$ & \multicolumn{2}{|c||}{$\mathrm{F}_{\text {EncGUM }}(j, 83)$} & \multicolumn{3}{|c||}{ p-values for two types of encompassing tests } \\
\hline & & & $j$ & $\mathrm{p}-$ value & \multicolumn{2}{|c||}{$F_{\text {Enc, }}$} & \multicolumn{2}{|c||}{$F_{\text {Enc, }}$} \\
\hline \hline AWM & 13 & 0.19 & 16 & 0.08 & $M_{1}$ vs $M_{j}$ & $M_{j}$ vs $M_{1}$ & $M_{1}$ vs $M_{j}$ & $M_{j}$ vs $M_{1}$ \\
\hline ICM & 11 & 0.21 & 18 & $0.00^{* *}$ & 0.75 & $0.006^{* *}$ & 0.24 & $0.00^{* *}$ \\
$\mathrm{P}^{*}$ & 12 & 0.21 & 17 & $0.00^{* *}$ & 0.06 & $0.00^{* *}$ & $0.03^{*}$ & $0.00^{* *}$ \\
$\mathrm{P}^{*}$ enh & 14 & 0.19 & 15 & $0.04^{*}$ & 0.11 & $0.04^{*}$ & $0.009^{* *}$ & $0.005^{* *}$ \\
NPC & 7 & 0.23 & 22 & $0.00^{* *}$ & & & & \\
\hline
\end{tabular}

Table 6: Encompassing tests with ICM as incumbent model

\begin{tabular}{||l|l|l|l|l||l|l||l|l||}
\hline$\Delta p$ model & $k$ & $\sigma_{\hat{\Delta}} \%$ & \multicolumn{2}{|c||}{$\mathrm{F}_{\text {EncGUM }}(j, 83)$} & \multicolumn{3}{|c||}{$p$-values for two types of encompassing tests } \\
\hline & & & $j$ & $\mathrm{p}$-value & \multicolumn{2}{|c|}{$F_{\text {Enc, }}$} & \multicolumn{2}{|c||}{$F_{\text {Enc, }}$} \\
\hline \hline ICM & 11 & 0.21 & 18 & $0.00^{* *}$ & $M_{1}$ vs $M_{j}$ & $M_{j}$ vs $M_{1}$ & $M_{1}$ vs $M_{j}$ & $M_{j}$ vs $M_{1}$ \\
\hline AWM & 13 & 0.19 & 16 & 0.08 & $0.006^{* *}$ & 0.75 & $0.00^{* *}$ & 0.24 \\
$\mathrm{P}^{*}$ & 12 & 0.21 & 17 & $0.00^{* *}$ & $0.002^{* *}$ & $0.000^{* *}$ & $0.017^{*}$ & $0.001^{* *}$ \\
$\mathrm{P}^{*}$ enh & 14 & 0.19 & 15 & $0.04^{*}$ & $0.003^{* *}$ & 0.26 & $0.000^{* *}$ & $0.013^{*}$ \\
NPC & 7 & 0.23 & 22 & $0.00^{* *}$ & & & & \\
\hline
\end{tabular}

\subsection{Comparing the forecasting properties of the models}

Appendix A shows graphs of 20 quarters of one step ahead forecasts with +/- two forecast errors to indicate the forecast uncertainty for the five models we have estimated. It is difficult to tell from the diagrams by means of "eyeball" econometrics whether there are any difference between them. So there is a need for formal tests: Table 7 provides a summary of the forecasting properties of the different inflation models as it reports RMSFEs along with their decomposition into forecast error bias and standard errors. The models are reestimated on a sample up to the start of the forecasting horizon, and then used to forecast quarterly inflation until 2000.3. Two different horizons are considered with 36 periods forecasts starting in 1991.4, and 20 periods forecasts starting in 1995.4. The first three lines of Table 7 shows the Root Mean Squared Forecast Error, RMSFE, of inflation from the AWM, and its decomposition into mean forecasting bias and standard deviation sdev. The other rows of the table shows the same three components of the RMSFE-decomposition for each of the other inflation models, measured relative to the results for the AWM, such that, e.g., a number greater than one indicates that the model has a larger

to estimate NPC on a single equation form to make it comparable to the other (single equation) models.

\footnotetext{
${ }^{30}$ Strictly speaking, the generic GUM is the union of all information sets we have used to create the general models in Sections 4.1-4.4. In the minimal nesting (parsimonious) GUM we have left out all variables that are not appearing in any of the five final equations and it is more precise to call this a pGUM.
} 
RMSFE than the AWM. For one step forecasts 20 quarters ahead, we find that all competing models beat the AWM on the RMSFE- and bias-criteria, whereas AWM is superior according to sdev.

Table 7: Forecasting the quarterly rate of inflation. RMSFE and its decomposition: bias, standard deviations and root mean squared forecast errors (RMSFE) of different inflation models, relative to the AWM.

\begin{tabular}{|c|c|c|c|}
\hline & & \multicolumn{2}{|c|}{ Forecasting $\hat{\Delta p}$} \\
\hline$\Delta_{4} p$ model & & $91.4-00.3$ & $95.4-00.3$ \\
\hline \multirow{3}{*}{ AWM } & RMSFE & 0.0022 & 0.0021 \\
\hline & bias & 0.0011 & 0.0016 \\
\hline & sdev & 0.0019 & 0.0014 \\
\hline \multirow{3}{*}{ ICM } & Rel. RMSFE & 1.08 & 0.82 \\
\hline & Rel. bias & 1.28 & 0.42 \\
\hline & Rel. sdev & 1.01 & 1.14 \\
\hline \multirow{3}{*}{$\mathrm{P}^{*}$} & Rel. RMSFE & 0.92 & 0.88 \\
\hline & Rel. bias & 0.55 & 0.38 \\
\hline & Rel. sdev & 1.02 & 1.26 \\
\hline \multirow{3}{*}{$\mathrm{P}^{*}$ _enh } & Rel. RMSFE & 0.76 & 0.73 \\
\hline & Rel. bias & 0.09 & 0.13 \\
\hline & Rel. sdev & 0.88 & 1.10 \\
\hline \multirow{3}{*}{ NPC } & Rel. RMSFE & 1.11 & 0.73 \\
\hline & Rel. bias & 0.20 & 0.06 \\
\hline & Rel. sdev & 1.29 & 1.12 \\
\hline
\end{tabular}

Table 8 and Table 9 show the results from forecast encompassing tests, regressing the forecast errors of model $1, \hat{\varepsilon}_{1 t}$, against the difference between the forecast errors of model $j$ and model 1 respectively, $\hat{\varepsilon}_{j t}-\hat{\varepsilon}_{1 t} \cdot{ }^{31}$ Under the null that there is no explanatory power in model $j$ beyond what is already reflected in model 1 , the expected regression coefficient is zero. In the table we report p-values when we run the forecast encompassing test in both directions. The AWM is used as benchmark (model 1) in Table 8 and the ICM is used as benchmark (model 1) in Table 9. In Table 8 there is evidence that AWM forecast encompasses three out of four competitors over 20 quarters (and the fourth - the $\mathrm{P}^{*}$-model enhanced - comes close to being encompassed at the 5 per cent level), while the reverse is not true. Over 36 quarters there is clear evidence that the AWM forecast encompasses the NPC, but is itself overwhelmingly forecast encompassed by the $\mathrm{P}^{*}$-model enhanced (based the same broad information set).

Table 8: Forecast encompassing tests over 36 and 20 periods, ending in 2000.3.

The AWM model is used as benchmark.

\begin{tabular}{|c|c|c|c|c|c|c|c|c|}
\hline \multirow[t]{3}{*}{ Model } & \multirow[t]{3}{*}{$k$} & \multirow[t]{3}{*}{$\sigma_{\hat{\Delta} p} \%$} & \multicolumn{2}{|c|}{$\overline{\mathrm{F}_{\text {EncGUM }}(j, 63)}$} & \multicolumn{4}{|c|}{ Forecast encompassing tests: p-values } \\
\hline & & & & & \multicolumn{2}{|c|}{$91.4-00.3$} & \multicolumn{2}{|c|}{$95.4-00.3$} \\
\hline & & & $j$ & p-value & $M_{1}$ vs $M_{j}$ & $M_{j}$ vs $M_{1}$ & $M_{1}$ vs $M_{j}$ & $M_{j}$ vs $M_{1}$ \\
\hline AWM & 13 & 0.19 & 16 & 0.08 & & & & \\
\hline ICM & 11 & 0.21 & 18 & $0.00^{* *}$ & 0.08 & 0.06 & 0.96 & $0.03^{*}$ \\
\hline $\mathrm{P}^{*}$ & 12 & 0.12 & 17 & $0.00^{* *}$ & $0.04^{*}$ & $0.02^{*}$ & 0.38 & $0.003^{* *}$ \\
\hline $\mathrm{P}^{*}$ enh & 14 & 0.19 & 15 & $0.04^{*}$ & $0.002^{* *}$ & 0.42 & 0.88 & 0.067 \\
\hline$N P \bar{C}$ & 7 & 0.23 & 22 & $0.00^{* *}$ & 0.21 & $0.00^{* *}$ & 0.35 & $0.03^{*}$ \\
\hline
\end{tabular}

In table 9 the ICM is used as benchmark. The ICM is not forecast encompassing any competitor over 20 quarters, but is, as noted above, itself forecast encom-

\footnotetext{
${ }^{31}$ Again, the forecast encompassing tests are based on two stage least squares estimates of the NPC.
} 
passed by the AWM. Over 36 quarters ICM forecast encompasses the NPC, and like the AWM - it is forecast encompassed by the enhanced version of the $\mathrm{P}^{*}$-model.

Table 9: Forecast encompassing tests over 36 and 20 periods, ending in 2000.3.

The ICM model is used as benchmark.

\begin{tabular}{||l|l|l|l|l||l|l||l|l||}
\hline Model & $k$ & $\sigma_{\hat{\Delta} p} \%$ & \multicolumn{2}{|c||}{$\mathrm{F}_{\text {EncGUM }}(j, 63)$} & \multicolumn{3}{|c||}{ Forecast encompassing tests: p-values } \\
\hline & & & & & \multicolumn{2}{|c|}{$91.4-00.3$} & \multicolumn{2}{|c||}{$95.4-00.3$} \\
\hline & & & $j$ & $\mathrm{p}$-value & $M_{1}$ vs $M_{j}$ & $M_{j}$ vs $M_{1}$ & $M_{1}$ vs $M_{j}$ & $M_{j}$ vs $M_{1}$ \\
\hline \hline ICM & 11 & 0.21 & 18 & $0.00^{* *}$ & & & & \\
\hline AWM & 13 & 0.19 & 16 & 0.08 & 0.06 & 0.08 & $0.03^{*}$ & 0.96 \\
P* & 12 & 0.12 & 17 & $0.00^{* *}$ & 0.11 & 0.06 & 0.87 & 0.06 \\
P*_enh & 14 & 0.19 & 15 & $0.04^{*}$ & $0.001^{* *}$ & 0.18 & 0.09 & 0.22 \\
NPC & 7 & 0.23 & 22 & $0.00^{* *}$ & 0.64 & $0.00^{* *}$ & 0.10 & 0.17 \\
\hline
\end{tabular}

\section{Conclusions}

The model comparisons in the final sections do not allow us to draw decisive conclusions. Some caveats no doubt apply: The presumptions of a clearly defined monetary policy for the economy under study, which are underlying the $\mathrm{P}^{*}$-model as it is laid out in Gerlach and Svensson (2003), is not favoured by adopting an observation period which starts nearly 30 years before the introduction of the Euro. ${ }^{32}$ Likewise, the ICM - with its focus on the labour market influx on inflation, is probably a better model description of the national economies than for the Euro area.

That said - from the model evaluation and the forecast comparisons - some comparative advantages seem to emerge in favour of the (reduced form) AWM inflation equation ${ }^{33}$ : It is the only model that encompasses a general unrestricted model and it forecast encompasses the competitors when tested on 20 quarters of one step ahead forecasts. The $\mathrm{P}^{*}$-model - based on the extended (AWM) information set forecast encompasses the other models based on 36 quarters of one step forecasts. In that context the NPC model appears to be a particularly poor model.

The results of the forecast competition are in accordance with the model evaluation in the preceding sections. The ICM is likely to suffer in forecasting due to the recursive instability in the long run (Table 2) as well as in the short run coefficients (Figure 6). Generally, we find that the models that are derived from the wider information sets (AWM and $\mathrm{P}^{*}$ enhanced) do better in forecasting than those based on a narrower information set, mainly prescribed by theory, like the $\mathrm{P}^{*}$-model proper and the NPC model.

\footnotetext{
${ }^{32}$ This point is however not relevant to the $\mathrm{P}^{*}$-model in its original tapping, see ?, where weight is put on the quantity equation and the stability of the money demand function. Fagan and Henry (1998) suggest that money demand may be more stable at the aggregated Euro area level than at the national levels.

${ }^{33}$ The AWM model may have been given a too favourable representation by our omission of the "calibrated" coefficient for the equilibrium correcting term from the factor price equation ecmp $p^{A W M}$ the wage equation, see comment to equation (25) in Appendix B.
} 


\section{References}

Anderson, T. W. and H. Rubin (1949). Estimation of the parameters of a single equation in a complete system of stochastic equations. Annals of Mathematical Statistics, 20, 46-63.

Anderson, T. W. and H. Rubin (1950). The asymptotic properties of estimates of the parameters of a single equation in a complete system of stochastic equations. Annals of Mathematical Statistics, 21, 570-582.

Angelini, E., J. Henry and R. Mestre (2001). A multi country trend indicator for Euro area inflation: Computation and properties. Working Paper 60, European Central Bank.

Bårdsen, G., Ø. Eitrheim, E. S. Jansen and R. Nymoen (2004a). The Econometrics of Macroeconomic Modelling. Oxford University Press, Oxford. Forthcoming.

Bårdsen, G. and P. G. Fisher (1999). Economic Theory and Econometric Dynamics in Modelling Wages and Prices in the United Kingdom. Empirical Economics, 24(3), 483-507.

Bårdsen, G., P. G. Fisher and R. Nymoen (1998). Business Cycles: Real Facts or Fallacies? In Strøm, S. (ed.), Econometrics and Economic Theory in the 20th Century: The Ragnar Frisch Centennial Symposium, no. 32 in Econometric Society Monograph Series, chap. 16, 499-527. Cambridge University Press, Cambridge.

Bårdsen, G., E. S. Jansen and R. Nymoen (2002). Testing the New Keynesian Phillips curve. Working paper ano 2002/5. Research Department, Norges Bank [Central Bank of Norway].

Bårdsen, G., E. S. Jansen and R. Nymoen (2003). Econometric Inflation Targeting. Econometrics Journal, 6, 429-460.

Bårdsen, G., E. S. Jansen and R. Nymoen (2004b). Econometric evaluation of the New Keynesian Phillips curve. Oxford Bulletin of Economics and Statistics. Forthcoming.

Barrell, R. and K. Dury (2003). Asymmetric labour markets in a converging Europe: do differences matter? National Institute Economic Review, (183), 56-65.

Batini, N. (2002). Euro area inflation persistence. Working Paper 201, European Central Bank.

Beyer, A., J. A. Doornik and D. F. Hendry (2000). Reconstructing Aggregate EuroZone Data. Journal of Common Market Studies, 38, 613-624.

Beyer, A., J. A. Doornik and D. F. Hendry (2001). Constructing Historical EuroZone Data. Economic Journal, 111, F102-F121.

Bofinger, P. (2000). Inflation targeting: Much ado about nothing new. Working paper, University of Würzburg. 
Bowdler, C. and E. S. Jansen (2004). A markup model of inflation for the Euro area. Working Paper 306, European Central Bank.

Calvo, G. A. (1983). Staggered prices in a utility maximizing framework. Journal of Monetary Economics, 12, 383-398.

Carlin, W. and D. Soskice (1990). Macroeconomics and the Wage Bargain. Oxford University Press, Oxford.

Clarida, R., J. Galí and M. Gertler (1999). The Science of Monetary Policy: A New Keynesian Perspective. Journal of Economic Literature, 37(4), 1661-1707.

Coenen, G. and J. L. Vega (2001). The demand for M3 in the Euro area. Journal of Applied Econometrics, 16, 727-748.

Coenen, G. and V. Wieland (2002). Inflation dynamics and international linkages: A model of the United States, the Euro area and Japan. Working Paper 181, European Central Bank.

Doornik, J. A. (1996). Testing Vector Autocorrelation and Heteroscedasticity in Dynamic Models. Working paper, Nuffield College, University of Oxford.

Doornik, J. A. and H. Hansen (1994). A Practical Test of Multivariate Normality. Unpublished paper, Nuffield College, University of Oxford.

Doornik, J. A. and D. F. Hendry (1997). Modelling Dynamic Systems Using PcFiml 9 for Windows. International Thomson Publishing, London.

Eitrheim, Ø. (2003). Testing the role of money in the inflation process. Unpublished paper, presented at EEA03 in Stockholm 20-24 August 2003, Norges Bank.

Eitrheim, Ø. and E. S. Jansen (2003). Evaluation of inflation models for the Euro area. Unpublished paper, Norges Bank.

Engle, R. F., D. F. Hendry and J.-F. Richard (1983). Exogeneity. Econometrica, $51,277-304$.

Ericsson, N. R. (1992). Parameter constancy, mean-square forecast errors, and measuring forecast performance. Journal of Policy Modelling, 14, 465-495.

Fabiani, S. and R. Mestre (2000). Alternative measures of the NAIRU in the Euro area: estimates and assessments. Working Paper 17, European Central Bank.

Fabiani, S. and R. Mestre (2001). A system approach for measuring the Euro area NAIRU. Working Paper 65, European Central Bank.

Fabiani, S. and J. Morgan (2003). Aggregation and Euro area Phillips curves. Working Paper 213, European Central Bank.

Fagan, G. and J. Henry (1998). Long run money demand in the EU: Evidence for area-wide aggregates. Empirical Economics, 23, 483-506. 
Fagan, G., J. Henry and R. Mestre (2001). An area-wide model (AWM) for the Euro area. Working Paper 42, European Central Bank.

Galí, J. and M. Gertler (1999). Inflation Dynamics: A Structural Econometric Analysis. Journal of Monetary Economics, 44 (2), 233-258.

Galí, J., M. Gertler and J. D. López-Salido (2001). European Inflation Dynamics. European Economic Review, 45, 1237-1270.

Gerlach, S. and L. E. O. Svensson (2003). Money and inflation in the euro area: A case for monetary indicators? Journal of Monetary Economics, 50, 1649-1672.

Godfrey, L. G. (1978). Testing for higher order serial correlation when the regressors include lagged dependent variables. Econometrica, 46, 1303-1313.

Hallman, J. J., R. D. Porter and D. H. Small (1991). Is the price level tied to the M2 monetary aggregate in the long run? American Economic Review, 81, 841-858.

Harbo, I., S. Johansen, B. Nielsen and A. Rahbek (1998). Asymptotic Inference on Cointegrating Rank in Partial System. Journal of Business 86 Economic Statistics, 16, 388-399.

Hendry, D. F. (2001). Modelling UK Inflation, 1875-1991. Journal of Applied Econometrics, 16, 255-275.

Hendry, D. F. and J. A. Doornik (2001). Empirical Econometric Modelling Using PcGive 10. Vol 1. Timberlake, London.

Hendry, D. F. and G. E. Mizon (1993). Evaluating dynamic econometric models by encompassing the VAR. In Phillips, P. C. B. (ed.), Models, Methods and Applications of Econometrics, 272-300. Basil Blackwell, Oxford.

Hendry, D. F. and J. F. Richard (1989). Recent developments in the theory of encompassing. In Cornet, B. and H. Tulkens (eds.), Contributions to Operations Research and Econometrics. The XXth Anniversary of CORE. MIT Press, Cambridge, MA.

Hodrick, R. J. and E. C. Prescott (1997). Postwar U.S. business cycles: An empirical investigation. Journal of Money, Credit and Banking, 29, 1-16.

Hoel, M. and R. Nymoen (1988). Wage Formation in Norwegian Manufacturing. An Empirical Application of a Theoretical Bargaining Model. European Economic Review, 32, 977-997.

Johansen, S. (1988). Statistical Analysis of Cointegration Vectors. Journal of Economic Dynamics and Control, 12, 231-254.

Johansen, S. (1992). Cointegration in Partial Systems and the Efficiency of SingleEquation Analysis. Journal of Econometrics, 52, 389-402.

Juselius, K. (1992). Domestic and Foreign Effects on Prices in an Open Economy: The Case of Denmark. Journal of Policy Modeling, 14, 401-428. 
Juselius, K. (2003). Wage, price, and unemployment dynamics and the convergence to purchasing power parity in the Euro area. Discussion Papers 03-01, Institute of Economics, University of Copenhagen.

Kolsrud, D. and R. Nymoen (1998). Unemployment and the Open Economy WagePrice Spiral. Journal of Economic Studies, 25, 450-467.

Koopmans, T. C., H. Rubin and R. B. Leibnik (1950). Measuring the equation systems of dynamic economics. In Koopmans, T. C. (ed.), Statistical inference in dynamic economic models, Cowles Commission Monograph 10, 53-237. Wiley, New York.

Korteweg, G. and F. Vijselaar (2002). A tale of eight legs on a fly. Unpublished paper, presented at IAOS Conference on the New Economy in London 27-29 August 2002, European Central Bank.

Layard, R. and S. Nickell (1986). Unemployment in Britain. Economica, 53, 121166. Special issue.

Layard, R., S. Nickell and R. Jackman (1991). Unemployment. Oxford University Press, Oxford.

Levin, A. T. and J. M. Piger (2003). Is inflation persistence intrinsic in industrial economies? Working paper 2002-023, revised may 2003, Federal Reserve Bank of St. Louis.

Marcellino, M. and G. E. Mizon (2001). Small-System Modelling of Real Wages, Inflation, Unemployment and Output Per Capita in Italy 1970-1994. Journal of Applied Econometrics, 16, 359-370.

Mavroeidis, S. (2002). Econometric Issues in Forward-Looking Monetary Models. Ph.D. thesis, Nuffield College, Oxford University.

Mizon, G. E. (1995). Progressive Modelling of Macroeconomic Time Series: The LSE Methodology. In Hoover, K. D. (ed.), Macroeconometrics: Developments, Tensions and Prospects, 107-169. Kluwer Academic Press, Dordrecht.

Mizon, G. M. and J. F. Richard (1986). The encompassing principle and its application to testing non-nested hypothesis. Econometrica, 54, 657-678.

Nicoletti Altimari, S. (2001). Does money lead inflation in the Euro area? Working Paper 63, European Central Bank.

OECD (2002). Employment Outlook. OECD, Paris.

Rahbek, A. and R. Mosconi (1999). Cointegration rank inference with stationary regressors in VAR models. Econometrics Journal, 2, 76-91.

Roberts, J. M. (1995). New Keynesian economics and the Phillips curve. Journal of Money, Credit and Banking, 27, 975-984. 
Roberts, J. M. (2001). How well does the New Keynesian sticky-price model fit the data? Finance and Economics Discussion Series 13, Federal Reserve Board of Governors.

Rødseth, A. (2000). Open Economy Macroeconomics. Cambridge University Press, Cambridge.

Rotemberg, J. J. (1982). Sticky prices in the United States. Journal of Political Economy, 90, 1187-1211.

Rudd, J. and K. Whelan (2004). New tests of the New Keynesian Phillips curve. Journal of Monetary Economics. Forthcoming.

Sargan, J. D. (1988). Lectures on Advanced Econometric Theory. Blackwell, Oxford.

Scarpetta, S., A. Bassanini, D. Pilat and P. Schreyer (2000). Economic growth in the OECD area: recent trends at the aggregated and sectoral level. Economics Department Working Papers 248, OECD.

Smets, F. and R. Wouters (2002). An estimated stochastic dynamic general equilibrium model of the Euro area. Working Paper 171, European Central Bank.

Smith, A. A. (1993). Estimating nonlinear time-series models using simulated vector autoregressions. Journal of Applied Econometrics, 8, S63-S84. Special issue: Econometric inference using simulation techniques.

Svensson, L. E. O. (2000). Open Economy Inflation Targeting. Journal of International Economics, 50, 155-183.

Taylor, J. B. (1979). Staggered wage setting in a macro model. American Economic Review, 69, 108-113.

Taylor, J. B. (1980). Aggregate dynamics and staggered contracts. Journal of Political Economy, 88, 1-23.

Trecroci, C. and J. L. Vega (2002). The information content of M3 for future inflation. Weltwirtschaftliches Archiv, 138, 22-53.

Vijselaar, F. and R. Albers (2002). New technologies and productivity growth in the Euro area. Working Paper 122, European Central Bank.

White, H. (1980). A Heteroskedasticity-Consistent Covariance Matrix Estimator and a Direct Test of Heteroskedasticity. Econometrica, 48, 817-838.

Willman, A. and A. Estrada (2002). The Spanish block of the ESCB-Multi-Country model. Working Paper 149, European Central Bank. 


\section{A One step forecasts - diagrams}
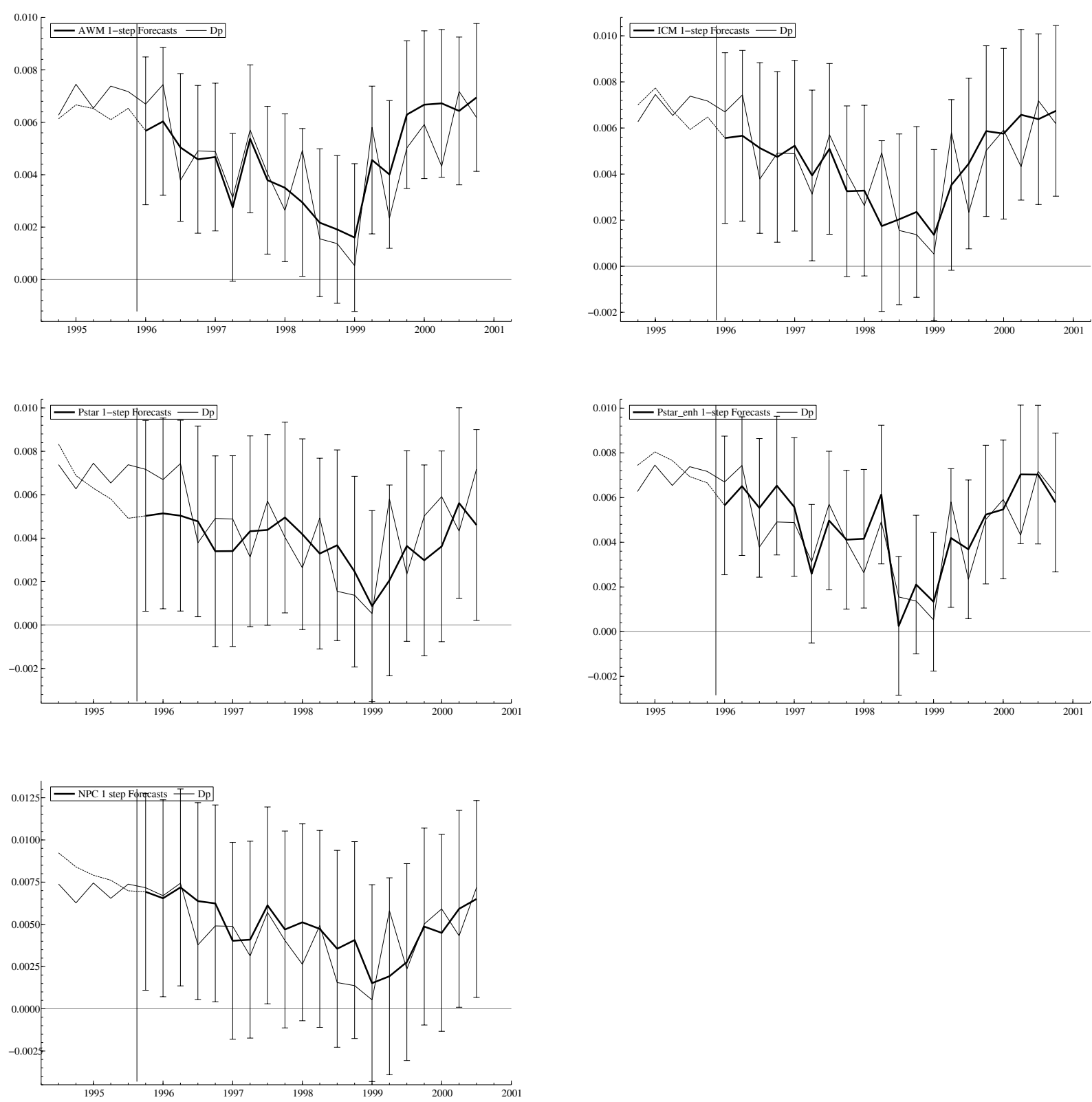

Figure 9: Forecasts of quarterly inflation in the Euro Area with 5 different models: over the period 1995.4 to 2000.3. The models are. First row: the Area Wide Model (left) and the ICM (right). Second row: The p-star model (left) and the enhanced Pstar (right) Bottom: The New Keynesian Phillips curve. The bars show $2 \mathrm{x}$ forecast errors. 


\section{B Wage price block of AWM}

In this Appendix we report results from reestimation on an extended dataset up to 2000.4 of the price and wage block of AWM from Fagan et al. (2001).

In the wage equation the growth in the wage share is the dependent variable (noting that $w s_{t}=u l c_{t}-p_{t}=w_{t}-p r_{t}-p_{t}$ ).

$$
\begin{aligned}
& \widehat{\Delta w s_{t}}=\underset{(0.015)}{0.015}+\underset{(0.08)}{0.24 \Delta w s_{t-1}} \\
& -\underset{(0.16)}{0.74} \Delta \Delta p_{t}-\underset{(0.17)}{0.48} \Delta \Delta p_{t-1}-\underset{(0.16)}{0.47} \Delta \Delta p_{t-2}-\underset{(0.15)}{0.35} \Delta \Delta p_{t-3} \\
& -\underset{(0.07)}{0.52} \Delta \Delta p r_{t}-\underset{(0.09)}{0.42} \Delta \Delta p r_{t-1}-\underset{(0.09)}{0.38} \Delta \Delta p r_{t-2}-\underset{(0.08)}{0.26} \Delta \Delta p r_{t-3} \\
& -\underset{(0.003)}{0.013}\left(u_{t-1}-\bar{u}_{t-1}\right)+\underset{(0.012)}{0.012}\left(q_{t}-\left(\overline{u l c}_{t}-(1-\beta)\right)\right)+\text { dummies } \\
& \sigma=0.0044 \\
& 1972.1-2000.4 \\
& F_{A R 1-5}(5,97)=0.78[0.57] \quad F_{A R C H 1-4}(4,94)=0.70[0.59] \\
& \text { Normality test } \chi^{2}(2)=0.52[0.77] \quad F_{\text {HETERO }}(24,77)=0.67[0.87] \\
& F_{\text {RESET }}(1,101)=0.13[0.91]
\end{aligned}
$$

We note that equilibrium correcting term $e c m p^{A W M}$ from the price equation below is insignificant in equation (25). In Fagan et al. (2001) equation (C.4) this equilibrium correcting term is given a predetermined coefficient of 0.1 , in order to improve the long run simulation properties of the AWM model as a whole. This leads to a significant deterioration of the equation ( $\sigma$ increases $20 \%$, there is a marked instability in parameters, etc). We have not explored the consequences of imposing this restriction on (25) for the reduced form AWM inflation equation (20), but it is likely to affect the forecasting performance negatively.

$$
\begin{aligned}
& \widehat{\Delta q_{t}}=\underset{(0.014)}{0.054}+\underset{(0.08)}{0.22} \Delta q_{t-1}+\underset{(0.04)}{0.26} \Delta \overline{u l c}_{t}+\underset{(0.05)}{0.08} \Delta \overline{u l c}_{t-1}+\underset{(0.04)}{0.15} \Delta \overline{u l c}_{t-2} \\
& +\underset{(0.01)}{0.03} \Delta p i_{t-1}-\underset{(0.012)}{0.045}\left(q_{t}-\left(\overline{u l c}_{t}-(1-\beta)\right)\right) \\
& \sigma=0.0024 \\
& \begin{array}{ll}
F_{\text {AR1-5 }}(5,102)=1.26[0.29] & F_{A R C H 1-4}(4,99)=0.63[0.64] \\
\text { Normality test } \quad \chi^{2}(2)=1.65[0.44] & F_{\text {HETERO }}(12,94)=1.04[0.41]
\end{array} \\
& 1972.3-2000.4 \\
& F_{R E S E T}(1,106)=0.41[0.52]
\end{aligned}
$$




$$
\begin{aligned}
& \widehat{\Delta p_{t}}=\underset{(0.0003)}{0.0012}+\underset{(0.03)}{0.19} \Delta p_{t-4}+\underset{(0.04)}{0.46} \Delta(q+t)_{t}+\underset{(0.04)}{0.21} \Delta(q+t)_{t-1} \\
& +\underset{(0.01)}{0.07} \Delta p i_{t}+\underset{(0.01)}{0.02} \Delta p i_{t-1}+\underset{(0.002)}{0.004} \Delta p_{t}^{\text {raw }} \\
& -0.056\left(p_{t-1}-0.94(q+t)_{t-1}-0.06 p i_{t-1}\right)+\text { dummies } \\
& \text { (0.019) } \\
& \sigma=0.0014 \\
& F_{A R 1-5}(5,103)=0.34[0.89] \\
& 1971.2-2000.4 \\
& \text { Normality test } \chi^{2}(2)=0.74[0.69] \\
& F_{R E S E T}(1,106)=3.79\left[0.05^{*}\right] \\
& F_{A R C H 1-4}(4,100)=1.43[0.23] \\
& F_{\text {HETERO }}(19,88)=2.30\left[0.005^{* *}\right]
\end{aligned}
$$

Combining the two price equation (26) and (27) leads to the reduced form (20), which we use in Section 4.

\section{Data}

The main body of data underlying the present paper are series collected from the database for the Area Wide model (update3, as of February 2003), see documentation in Fagan et al. (2001). The Euro area aggregates are constructed from a wide range of national and international sources, the main principle has been to weight together national accounts data for the 11 EMU member countries, using logs of the country series and fixed weights for each country. The weights used are constant gdp at market prices (PPP) in 1995 and they are applied for both nominal and real variables. Deflators are then calculated, see Fagan and Henry (1998) for details. This amounts to using a set fixed PPP exchange rates between the national currencies, calculated for the year 1995, to convert all series to a common currency (i.e. Euro). ${ }^{34}$ The data series for imports and exports includes intra Euro area trade, since there are no statistical data available recording the net imports and exports between the Euro area and the Rest of the World. To avoid a break in the German data series due to German unification in 1990, AWM uses re-scaled West German data series (by the ratio of the two series at the start of whole Germany series) for the pre-unification years.

\section{C.1 The AWM data series}

The following series have been used from the AWM database:

$$
\begin{aligned}
& \text { PCD - Private consumption deflator } \\
& \text { WIN - Total compensation to employees }
\end{aligned}
$$

\footnotetext{
${ }^{34}$ An alternative aggregation method has been suggested by Beyer et al. (2001) (confer also Beyer et al. (2000)). They argue that aggregation across individual countries is problematic because of past exchange rate changes. Hence, a more appropriate method, which aggregates exactly when exchange rates are fixed, consists in aggregating weighted within-country growth rates to obtain euro-zone growth rates and cumulating this euro-zone growth rate to obtain aggregated levels. The aggregate of the implicit deflator price index coincides with the implicit deflator obtained from the aggregated nominal and real data.
} 
YER - Real gdp

$\mathrm{ULC}=\mathrm{WIN} / \mathrm{YER}$ - Unit labour costs

URX - Rate of unemployment

MTD - National accounts imports deflator (incl. intra Eurozone trade)

LNN - Total employment (number of heads)

LPROD $=$ YER/LNN - Labour productivity

COMPR - Weighted average of oil and non-oil world commodity prices, USD

EEN - Nominal effective exchange rate (Euro)

YFD - Gdp deflator at factor prices

YED - Gdp deflator at market values

URT - trend unemployment

ULT - trend unit labour costs

TIN - total indirect taxes (net of subsidies)

YFN - Nominal gdp at factor prices

LTN - Long term interest rate

STN - Short term interest rate

Variables used when estimating the AWM wage price block, cf. section 2.1:

$p=\log (\mathrm{PCD})$

$w=\log (\mathrm{WIN} / \mathrm{LNN})$

$p r=\log (\mathrm{LPROD})$

$w s=w-p r-p$

$u l c=\log (\mathrm{ULC})(=w-p r)$

$u=\log (\mathrm{URX})$

$\bar{u}=\log (\mathrm{URT})$

$q=\log (\mathrm{YFD})$

$\overline{u l c}=\log (\mathrm{ULT})$

$p i=\log (\mathrm{MTD})$

$p^{\text {raw }}=\log (\mathrm{COMPR} \cdot \mathrm{EEN})$

$t=\log (1+\mathrm{TIN} / \mathrm{YFN})$

Additional variables used when estimating the ICM model:

$y=\log (\mathrm{YER})$

$y^{*}=$ trend of $y$, using the Hodrick-Prescott filter with $\lambda=1600$

gap $=y-y^{*}$.

Additional variables used when estimating the $P^{*}$ model:

$m=\log (\mathrm{M} 3)$, where M3 is a merged series for money, see Appendix C.3.

$p y=\log (\mathrm{YED})$

$v=p y-y-m$

$v^{*}=$ trend of $v$, using the Hodrick-Prescott filter with $\lambda=400$.

$p y^{*}=m+v^{*}-y^{*}$

$r m=m-p y$

$r m^{*}=m-p y^{*}$

$s=\mathrm{LTN}-\mathrm{STN}$

$s^{*}=$ trend of $s$, using the Hodrick-Prescott filter with $\lambda=1600$

sgap $=s-s^{*}$

$\Delta_{4} \widetilde{p}=$ trend of $\Delta_{4} p$, using the Hodrick Prescott filter with $\lambda=6400$ 


$$
\begin{aligned}
& \Delta_{4} \text { pgap }=\Delta_{4} p-\Delta_{4} \widetilde{p} \\
& \Delta_{4} \widetilde{m}=\Delta_{4} \widetilde{p}+\Delta_{4} y^{*}-\Delta_{4} v^{*} \\
& \Delta_{4} m g a p=\Delta_{4} m-\Delta_{4} \widetilde{m}
\end{aligned}
$$
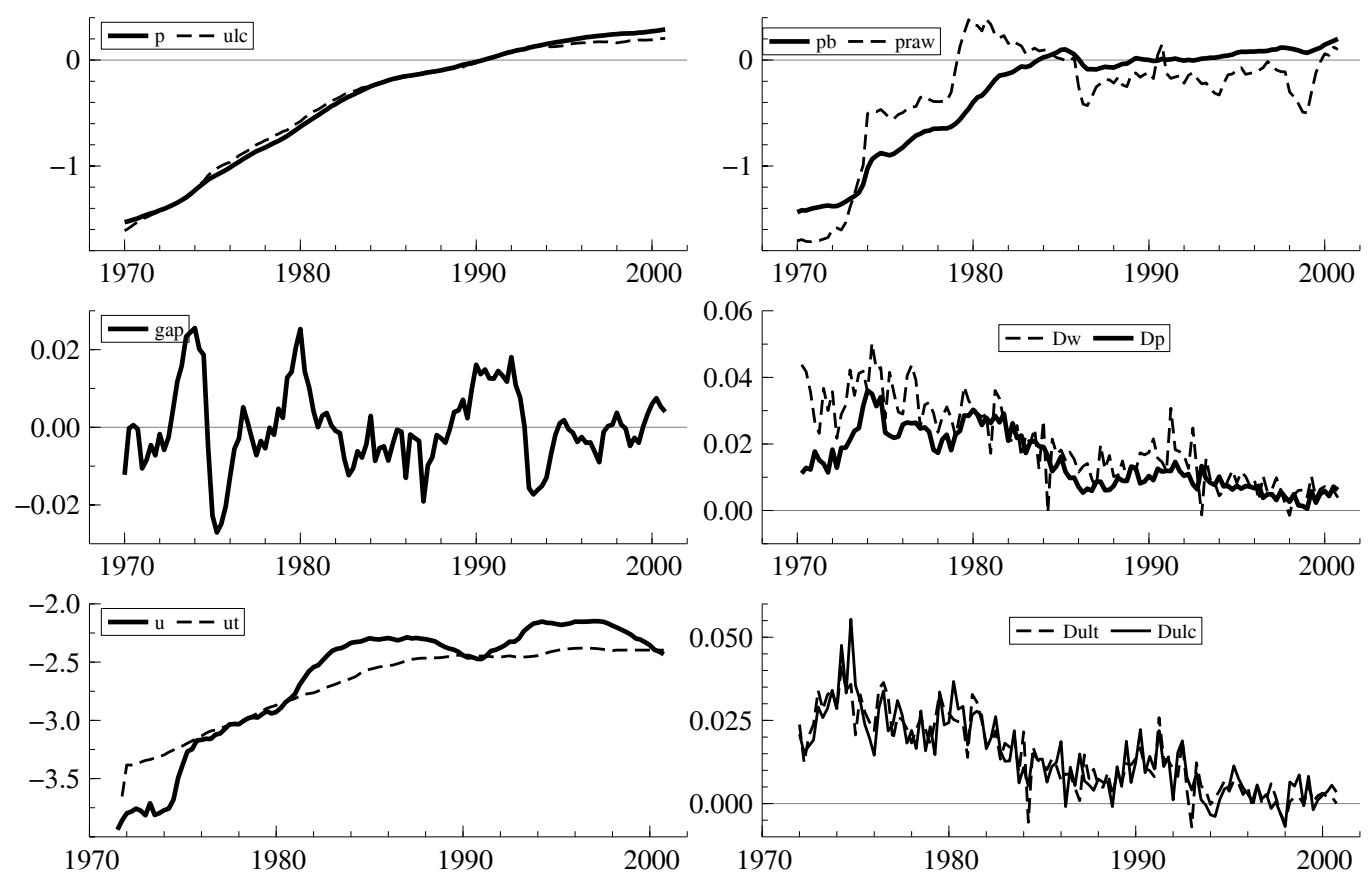

Figure 10: Data series used in the empirical analyses

\section{C.2 Alternative data for labour input - Hours worked}

As we alluded to in Section 3.3, we have investigated an alternative labour input based on total number of hours worked (for total employment) in the Euro area, HW_Euro. The series are constructed by aggregating country data across the Euro area from the following sources: Total employment data were taken from national accounts and average working hours from OECD (2002) and Scarpetta et al. (2000), see Vijselaar and Albers (2002) and Korteweg and Vijselaar (2002) for further documentation. The resulting series for total hours worked are plotted against total employment in levels, LNN, (means and range adjusted to the same scaling) and as quarterly growth rates in Figure 11. Figure 12 shows the growth rates for productivity, $\Delta p r$, with the two alternative labour input measures. 

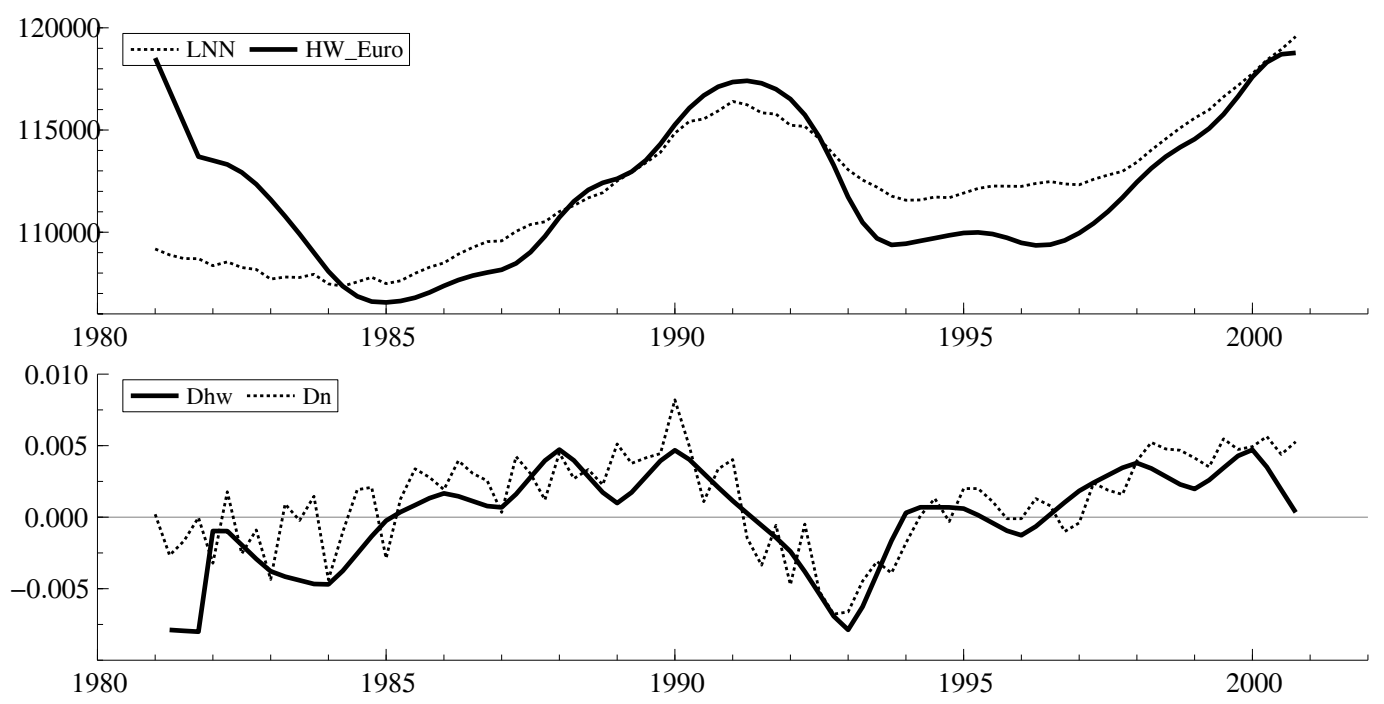

Figure 11: In the upper graph the two measures for the labour input are plotted together (means and range are given the same scaling): Total employment (LNN) is the dotted line whereas hours worked (smoothed series from annual data) is the solid line. The lower figure shows growth rates for the two series.

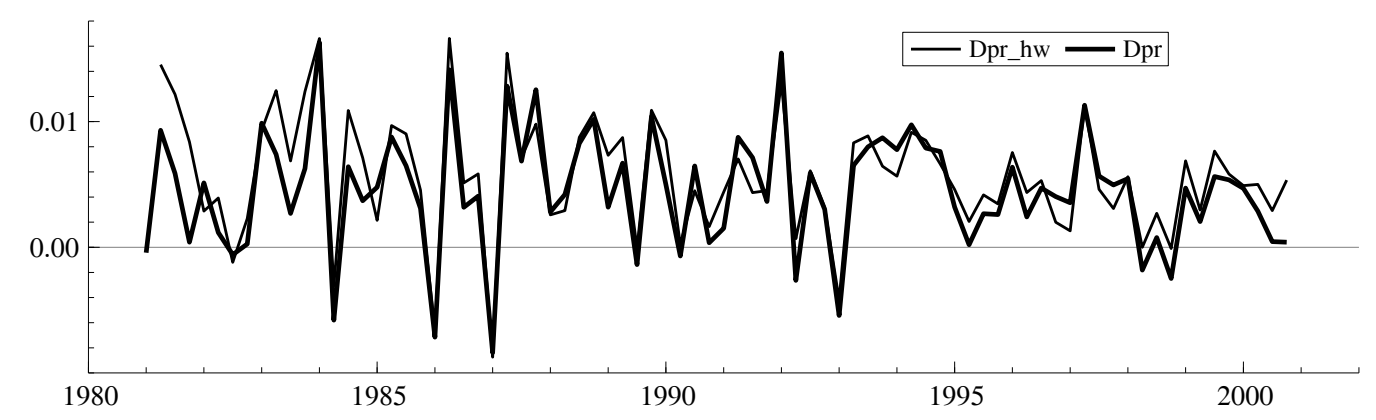

Figure 12: The growth rates for productivity with the two alternative labour input measures. The solid line is for productivity defined as real GDP divided by total unemployment (LNN) whereas the thin line is in terms of hours worked.

\section{C.3 Variables specific to the $\mathrm{P}^{*}$-model}

The $\mathrm{P}^{*}$ model is presented in section 2.2, and the variables are defined in Appendix C.1. In Figure 13 we have plotted the source data for the money stock variable (M3), as quarterly growth rates.. For the observations $1970.1-1979.4$ and 2000.4 it is the series M.U2.M3B0.ST.SA from the ECB databank, whereas the observations 1980.1 - 2000.3 are from Gerlach and Svensson (2003), who in turn have collected the data for 1980.1 - 1997.4 from Coenen and Vega (2001), who give a detailed definition (pp. 370-371). The two series do not overlap completely as there are some large 
discrepancies, notably in 1990.2 (German unification) and 1999.1 (the launching of the Euro)

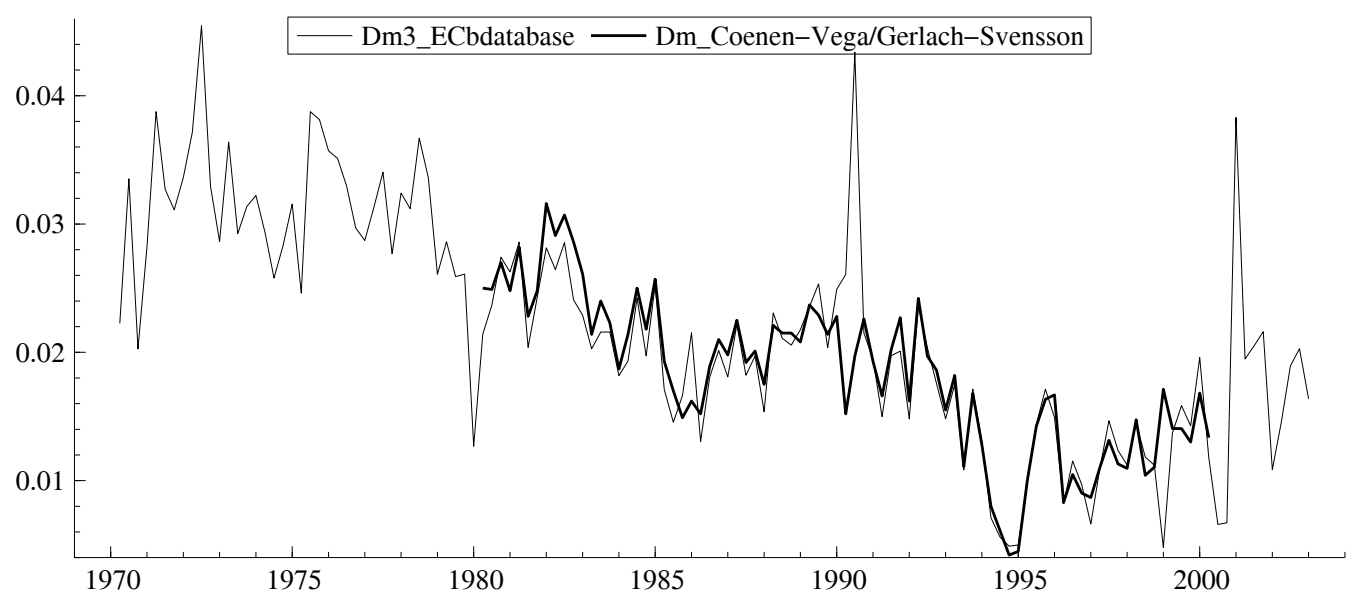

Figure 13: The M3 data series (M.U2.M3B0.ST.SA) plotted against the shorter M3 seiries obtained from Gerlach and Svensson (2003), which in turn are based on data from Coenen and Vega (2001). Quarterly growth rates.

Figure 14 shows the gdp deflator, the equilibrium price level $\left(p y^{*}\right)$ and their difference, whereas Figure 15 shows the corresponding graphs for real money.
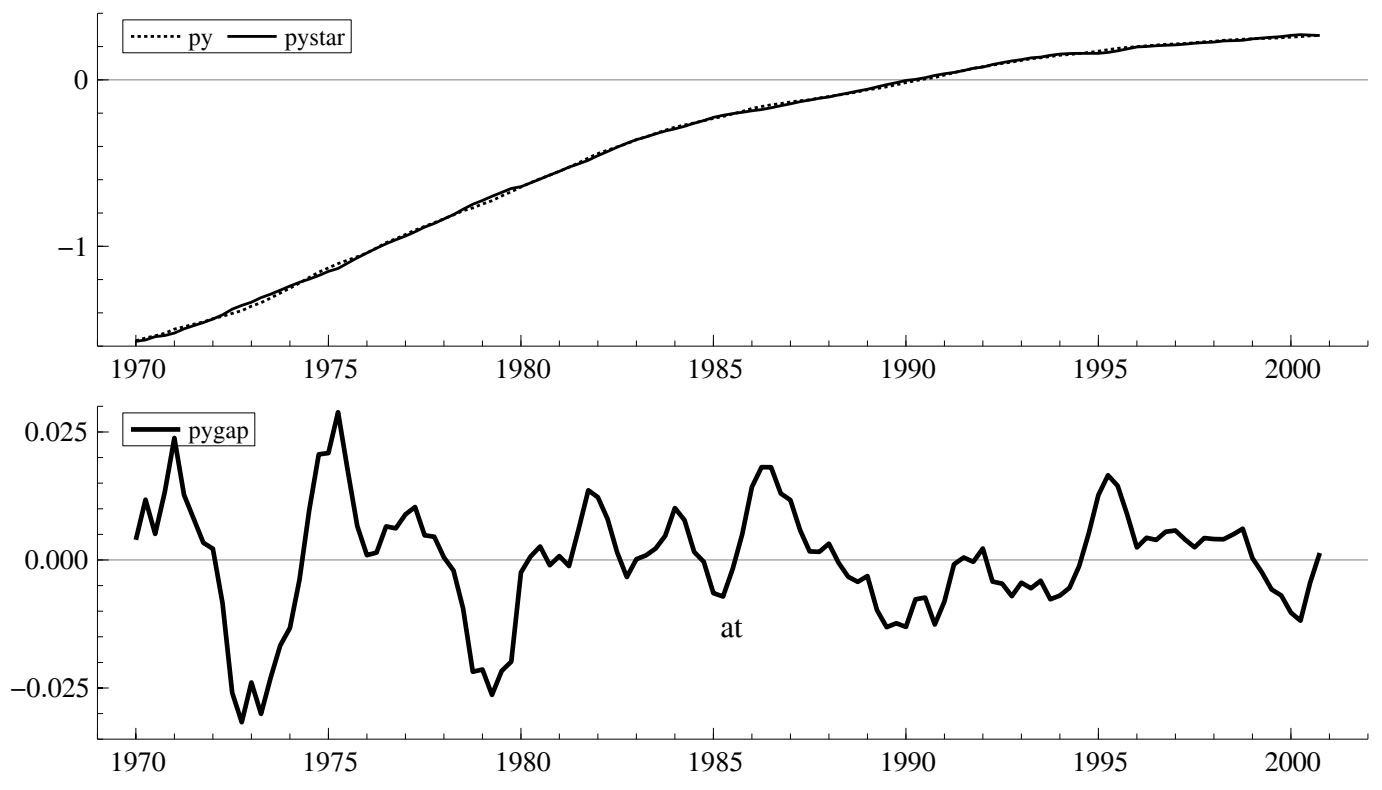

Figure 14: The upper graphs show the GDP deflator and the equilibrium price level $\left(\mathrm{p}^{*}\right)$, whereas the lower graph is their difference, i.e., the price gap, used in the $\mathrm{P}^{*}$-model. 


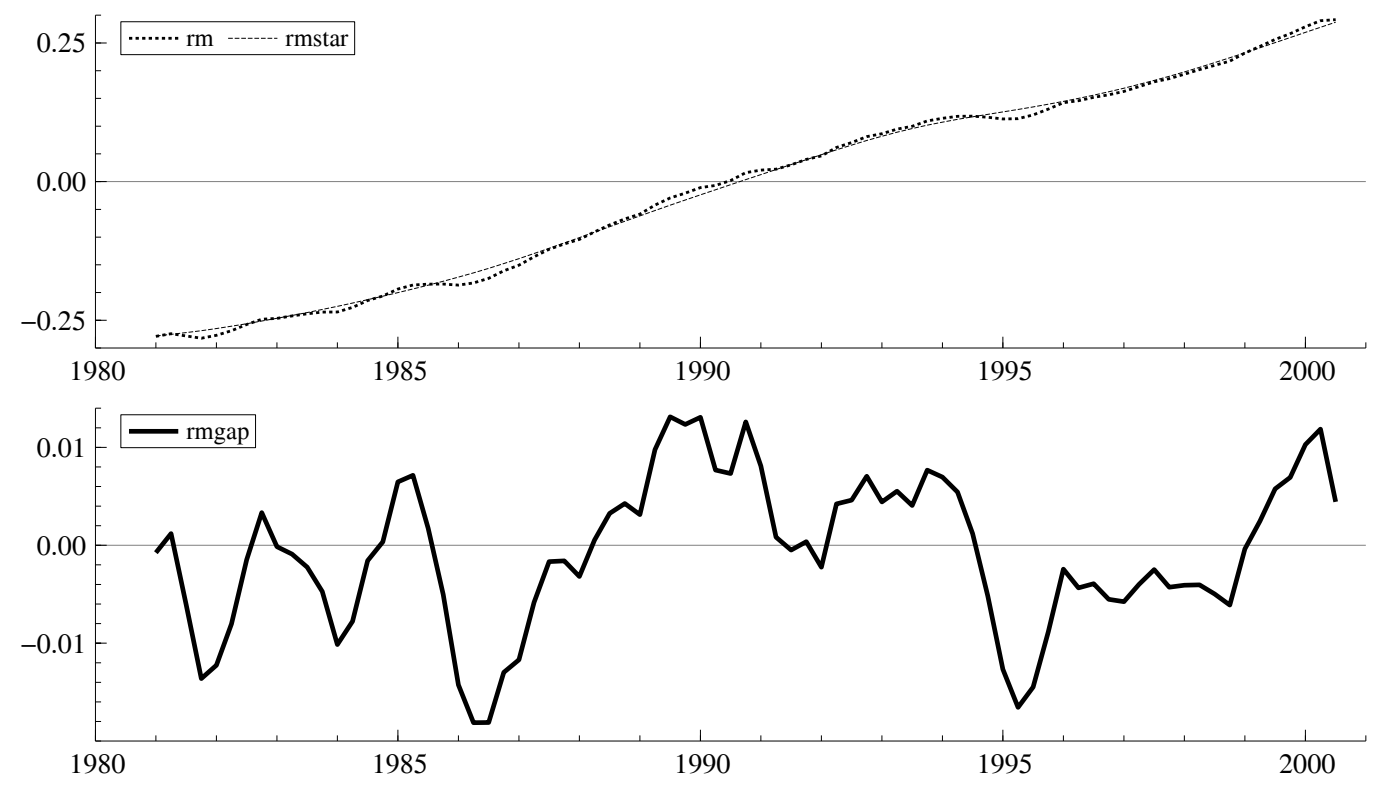

Figure 15: The upper graphs show real money and the equilibrium real money, whereas the lower graph is their difference, i.e. the real money gap, used in the $\mathrm{P}^{*}$-model.

Figures 16 and 17 show the alternative measures for $\Delta_{4} \widetilde{p}$ and $\Delta_{4} \widetilde{m}$, the reference paths for inflation and for real money. In our empirical study we have let the reference value for inflation vary with the actual level of smoothed inflation which is shown by the solid line in upper half of Figure 16. As we alluded to in section 2.2, Gerlach and Svensson (2003) introduce and estimate a measure for the inflation target Euro area as gradual adjustment to the (implicit) inflation target of the Bundesbank, see Bofinger (2000), and they interpret the gradual adjustment as a way of capturing a monetary policy convergence process in the Euro area throughout their estimation period (1980.1 - 2001.2). In Figure 16 the Gerlach-Svensson measure is plotted for the period 1985.1 - 2000.2. Figure 17 shows the analogous graphs for real money. 

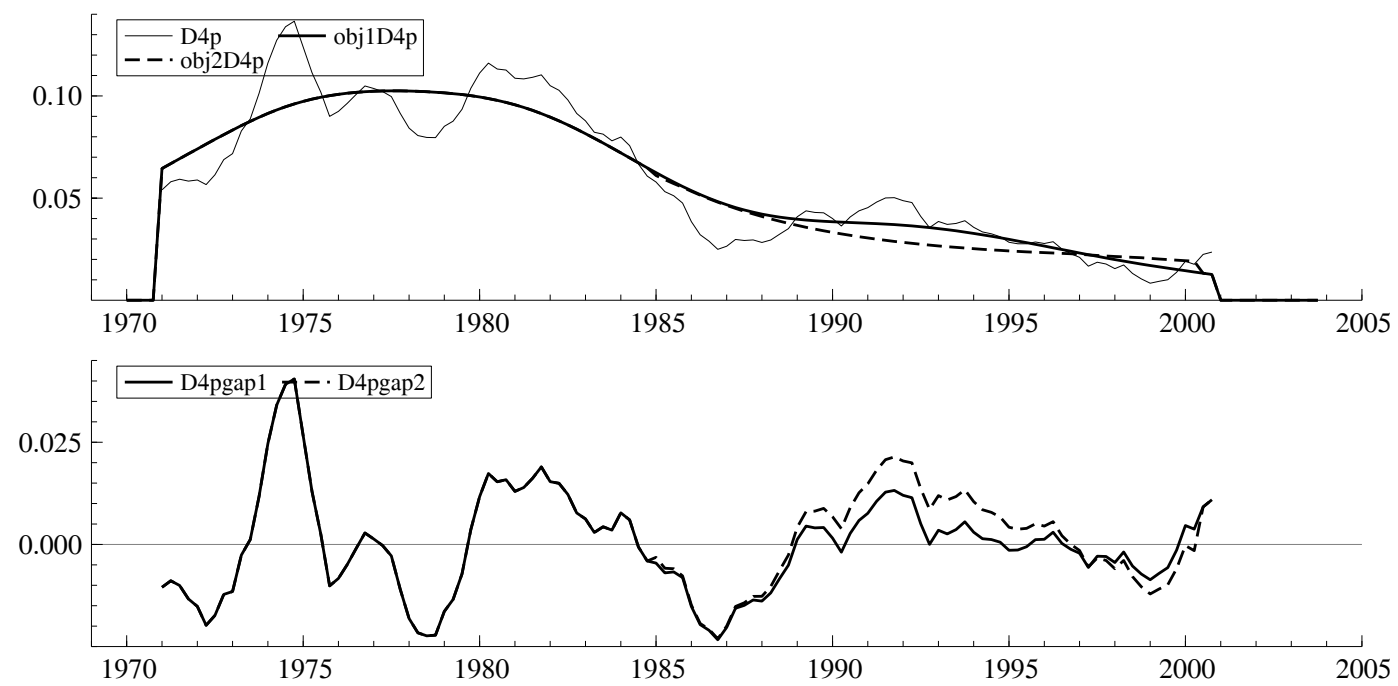

Figure 16: The upper figure shows actual annual inflation plotted against two alternative measures of the reference path for inflation. The solid line shows the HP trend of inflation and the dotted line shows the case where the Gerlach Svensson target variable is substituted for the HP trend for the subsample 1985.1-2000.2.. The lower graphs show the corresponding D4pgap variables in the same cases.
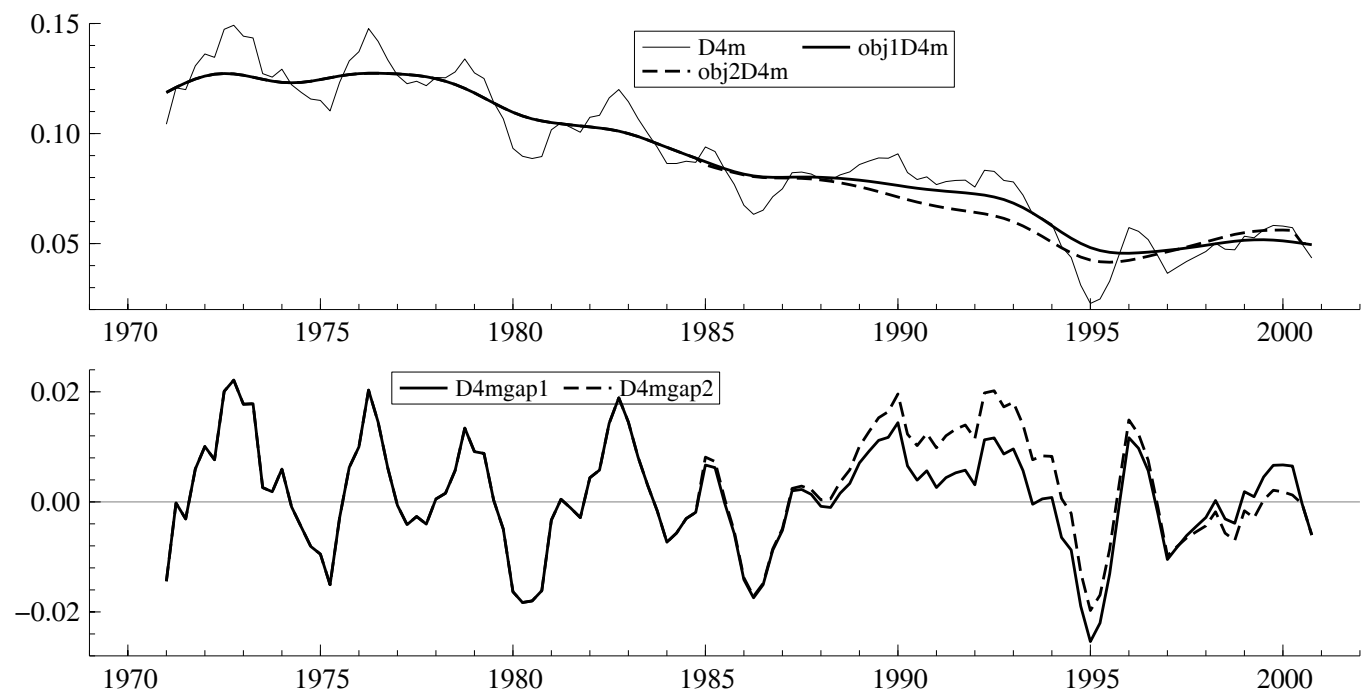

Figure 17: The upper figure shows actual annual money growth plotted against the alternative measures of the reference path for money growth. The solid line is the reference path derived from the HP trend of inflation and the dotted line is the alternative, which is derived from inflation reference path with the Gerlach Svensson target variable substituted for the HP trend for the subsample 1985.1-2000.2. The lower graphs show the corresponding D4mgap variables in the same cases. 


\section{European Central Bank working paper series}

For a complete list of Working Papers published by the ECB, please visit the ECB's website (http://www.ecb.int).

202 "Aggregate loans to the euro area private sector" by A. Calza, M. Manrique and J. Sousa, January 2003.

203 "Myopic loss aversion, disappointment aversion and the equity premium puzzle" by D. Fielding and L. Stracca, January 2003.

204 "Asymmetric dynamics in the correlations of global equity and bond returns" by L. Cappiello, R.F. Engle and K. Sheppard, January 2003.

205 "Real exchange rate in an inter-temporal n-country-model with incomplete markets" by B. Mercereau, January 2003.

206 "Empirical estimates of reaction functions for the euro area" by D. Gerdesmeier and B. Roffia, January 2003.

207 "A comprehensive model on the euro overnight rate” by F. R. Würtz, January 2003.

208 "Do demographic changes affect risk premiums? Evidence from international data" by A. Ang and A. Maddaloni, January 2003.

209 "A framework for collateral risk control determination" by D. Cossin, Z. Huang, D. Aunon-Nerin and F. González, January 2003.

210 "Anticipated Ramsey reforms and the uniform taxation principle: the role of international financial markets” by S. Schmitt-Grohé and M. Uribe, January 2003.

2II “Self-control and savings" by P. Michel and J.P. Vidal, January 2003.

212 "Modelling the implied probability of stock market movements" by E. Glatzer and M. Scheicher, January 2003.

213 “Aggregation and euro area Phillips curves” by S. Fabiani and J. Morgan, February 2003.

2I4 “On the selection of forecasting models" by A. Inoue and L. Kilian, February 2003.

215 "Budget institutions and fiscal performance in Central and Eastern European countries" by H. Gleich, February 2003.

216 "The admission of accession countries to an enlarged monetary union: a tentative assessment” by M. Ca'Zorzi and R. A. De Santis, February 2003.

217 "The role of product market regulations in the process of structural change" by J. Messina, March 2003. 
218 "The zero-interest-rate bound and the role of the exchange rate for monetary policy in Japan" by G. Coenen and V. Wieland, March 2003.

219 "Extra-euro area manufacturing import prices and exchange rate pass-through" by B. Anderton, March 2003.

220 "The allocation of competencies in an international union: a positive analysis" by M. Ruta, April 2003.

221 "Estimating risk premia in money market rates" by A. Durré, S. Evjen and R. Pilegaard, April 2003.

222 "Inflation dynamics and subjective expectations in the United States" by K. Adam and M. Padula, April 2003.

223 "Optimal monetary policy with imperfect common knowledge" by K. Adam, April 2003.

224 "The rise of the yen vis-à-vis the ("synthetic") euro: is it supported by economic fundamentals?" by C. Osbat, R. Rüffer and B. Schnatz, April 2003.

225 "Productivity and the ("synthetic") euro-dollar exchange rate" by C. Osbat, F. Vijselaar and B. Schnatz, April 2003.

226 "The central banker as a risk manager: quantifying and forecasting inflation risks" by L. Kilian and S. Manganelli, April 2003.

227 "Monetary policy in a low pass-through environment" by T. Monacelli, April 2003.

228 "Monetary policy shocks - a nonfundamental look at the data" by M. Klaeffing, May 2003.

229 “How does the ECB target inflation?" by P. Surico, May 2003.

230 "The euro area financial system: structure, integration and policy initiatives" by P. Hartmann, A. Maddaloni and S. Manganelli, May 2003.

231 "Price stability and monetary policy effectiveness when nominal interest rates are bounded at zero" by G. Coenen, A. Orphanides and V. Wieland, May 2003.

232 "Describing the Fed's conduct with Taylor rules: is interest rate smoothing important?" by E. Castelnuovo, May 2003.

233 "The natural real rate of interest in the euro area" by N. Giammarioli and N. Valla, May 2003.

234 "Unemployment, hysteresis and transition" by M. León-Ledesma and P. McAdam, May 2003.

235 "Volatility of interest rates in the euro area: evidence from high frequency data" by N. Cassola and C. Morana, June 2003. 
236 "Swiss monetary targeting 1974-1996: the role of internal policy analysis" by G. Rich, June 2003.

237 "Growth expectations, capital flows and international risk sharing” by O. Castrén, M. Miller and R. Stiegert, June 2003.

238 "The impact of monetary union on trade prices" by R. Anderton, R. E. Baldwin and D. Taglioni, June 2003.

239 "Temporary shocks and unavoidable transitions to a high-unemployment regime" by W. J. Denhaan, June 2003.

240 "Monetary policy transmission in the euro area: any changes after EMU?" by I. Angeloni and M. Ehrmann, July 2003.

24I Maintaining price stability under free-floating: a fearless way out of the corner?" by C. Detken and V. Gaspar, July 2003.

242 "Public sector efficiency: an international comparison" by A. Afonso, L. Schuknecht and V. Tanzi, July 2003.

243 “Pass-through of external shocks to euro area inflation” by E. Hahn, July 2003.

244 "How does the ECB allot liquidity in its weekly main refinancing operations? A look at the empirical evidence" by S. Ejerskov, C. Martin Moss and L. Stracca, July 2003.

245 "Money and payments: a modern perspective" by C. Holthausen and C. Monnet, July 2003.

246 "Public finances and long-term growth in Europe - evidence from a panel data analysis" by D. R. de Ávila Torrijos and R. Strauch, July 2003.

247 "Forecasting euro area inflation: does aggregating forecasts by HICP component improve forecast accuracy?" by K. Hubrich, August 2003.

248 "Exchange rates and fundamentals" by C. Engel and K. D. West, August 2003.

249 "Trade advantages and specialisation dynamics in acceding countries" by A. Zaghini, August 2003.

250 "Persistence, the transmission mechanism and robust monetary policy" by I. Angeloni, G. Coenen and F. Smets, August 2003.

25I "Consumption, habit persistence, imperfect information and the lifetime budget constraint" by A. Willman, August 2003.

252 "Interpolation and backdating with a large information set" by E. Angelini, J. Henry and M. Marcellino, August 2003.

253 "Bond market inflation expectations and longer-term trends in broad monetary growth and inflation in industrial countries, 1880-200I” by W. G. Dewald, September 2003. 
254 "Forecasting real GDP: what role for narrow money?" by C. Brand, H.-E. Reimers and F. Seitz, September 2003.

255 "Is the demand for euro area M3 stable?" by A. Bruggeman, P. Donati and A. Warne, September 2003.

256 "Information acquisition and decision making in committees: a survey" by K. Gerling, H. P. Grüner, A. Kiel and E. Schulte, September 2003.

257 “Macroeconomic modelling of monetary policy" by M. Klaeffling, September 2003.

258 "Interest rate reaction functions and the Taylor rule in the euro area" by P. GerlachKristen, September 2003.

259 "Implicit tax co-ordination under repeated policy interactions" by M. Catenaro and J.-P. Vidal, September 2003.

260 "Aggregation-theoretic monetary aggregation over the euro area, when countries are heterogeneous" by W. A. Barnett, September 2003.

261 "Why has broad money demand been more stable in the euro area than in other economies? A literature review" by A. Calza and J. Sousa, September 2003.

262 "Indeterminacy of rational expectations equilibria in sequential financial markets" by P. Donati, September 2003.

263 "Measuring contagion with a Bayesian, time-varying coefficient model" by M. Ciccarelli and A. Rebucci, September 2003.

264 "A monthly monetary model with banking intermediation for the euro area" by A. Bruggeman and M. Donnay, September 2003.

265 "New Keynesian Phillips Curves: a reassessment using euro area data" by P. McAdam and A. Willman, September 2003.

266 "Finance and growth in the EU: new evidence from the liberalisation and harmonisation of the banking industry" by D. Romero de Ávila, September 2003.

267 "Comparing economic dynamics in the EU and CEE accession countries" by R. Süppel, September 2003.

268 "The output composition puzzle: a difference in the monetary transmission mechanism in the euro area and the US" by I. Angeloni, A. K. Kashyap, B. Mojon and D. Terlizzese, September 2003.

269 "Zero lower bound: is it a problem with the euro area?" by G. Coenen, September 2003.

270 "Downward nominal wage rigidity and the long-run Phillips curve: simulation-based evidence for the euro area" by G. Coenen, September 2003.

27I "Indeterminacy and search theory" by N. Giammarioli, September 2003. 
272 "Inflation targets and the liquidity trap" by M. Klaeffling and V. López Pérez, September 2003.

273 "Definition of price stability, range and point inflation targets: the anchoring of long-term inflation expectations” by E. Castelnuovo, S. Nicoletti-Altimari and D. RodriguezPalenzuela, September 2003.

274 "Interpreting implied risk neutral densities: the role of risk premia" by P. Hördahl and D. Vestin, September 2003.

275 "Identifying the monetary transmission mechanism using structural breaks" by A. Beyer and R. Farmer, September 2003.

276 "Short-term estimates of euro area real GDP by means of monthly data" by G. Rünstler, September 2003.

277 "On the indeterminacy of determinacy and indeterminacy" by A. Beyer and R. Farmer, September 2003.

278 "Relevant economic issues concerning the optimal rate of inflation" by D. R. Palenzuela, G. Camba-Méndez and J. Á. García, September 2003.

279 "Designing targeting rules for international monetary policy cooperation" by G. Benigno and P. Benigno, October 2003.

280 “Inflation, factor substitution and growth" by R. Klump, October 2003.

28I "Identifying fiscal shocks and policy regimes in OECD countries" by G. de Arcangelis and S. Lamartina, October 2003.

282 "Optimal dynamic risk sharing when enforcement is a decision variable" by T. V. Koeppl, October 2003.

283 "US, Japan and the euro area: comparing business-cycle features” by P. McAdam, November 2003.

284 "The credibility of the monetary policy 'free lunch"' by J. Yetman, November 2003.

285 "Government deficits, wealth effects and the price level in an optimizing model" by B. Annicchiarico, November 2003.

286 "Country and sector-specific spillover effects in the euro area, the United States and Japan" by B. Kaltenhaeuser, November 2003.

287 “Consumer inflation expectations in Poland” by T. Łyziak, November 2003.

288 "Implementing optimal control cointegrated I(I) structural VAR models" by F. V. Monti, November 2003.

289 "Monetary and fiscal interactions in open economies" by G. Lombardo and A. Sutherland, November 2003. 
290 “Inflation persistence and robust monetary policy design” by G. Coenen, November 2003.

29I “Measuring the time-inconsitency of US monetary policy” by P. Surico, November 2003.

292 "Bank mergers, competition and liquidity" by E. Carletti, P. Hartmann and G. Spagnolo, November 2003.

293 “Committees and special interests” by M. Felgenhauer and H. P. Grüner, November 2003.

294 "Does the yield spread predict recessions in the euro area?" by F. Moneta, December 2003.

295 “Optimal allotment policy in the eurosystem's main refinancing operations?" by C. Ewerhart, N. Cassola, S. Ejerskov and N. Valla, December 2003.

296 "Monetary policy analysis in a small open economy using bayesian cointegrated structural VARs?" by M. Villani and A. Warne, December 2003.

297 “Measurement of contagion in banks' equity prices” by R. Gropp and G. Moerman, December 2003.

298 "The lender of last resort: a 2 I st century approach" by X. Freixas, B. M. Parigi and J.-C. Rochet, December 2003.

299 "Import prices and pricing-to-market effects in the euro area” by T. Warmedinger, January 2004.

300 "Developing statistical indicators of the integration of the euro area banking system" by M. Manna, January 2004.

301 “Inflation and relative price asymmetry” by A. Rátfai, January 2004.

302 “Deposit insurance, moral hazard and market monitoring” by R. Gropp and J. Vesala, February 2004.

303 "Fiscal policy events and interest rate swap spreads: evidence from the EU" by A. Afonso and R. Strauch, February 2004.

304 "Equilibrium unemployment, job flows and inflation dynamics" by A. Trigari, February 2004.

305 “A structural common factor approach to core inflation estimation and forecasting" by C. Morana, February 2004.

306 "A markup model of inflation for the euro area" by C. Bowdler and E. S. Jansen, February 2004.

307 "Budgetary forecasts in Europe - the track record of stability and convergence programmes" by R. Strauch, M. Hallerberg and J. von Hagen, February 2004.

308 "International risk-sharing and the transmission of productivity shocks" by G. Corsetti, L. Dedola and S. Leduc, February 2004.

309 "Monetary policy shocks in the euro area and global liquidity spillovers" by J. Sousa and A. Zaghini, February 2004.

310 "International equity flows and returns: A quantitative equilibrium approach" by R. Albuquerque, G. H. Bauer and M. Schneider, February 2004.

311 "Current account dynamics in OECD and EU acceding countries - an intertemporal approach" by M. Bussière, M. Fratzscher and G. Müller, February 2004. 
312 "Similarities and convergence in G-7 cycles" by F. Canova, M. Ciccarelli and E. Ortega, February 2004.

313 "The high-yield segment of the corporate bond market: a diffusion modelling approach for the United States, the United Kingdom and the euro area" by G. de Bondt and D. Marqués, February 2004.

314 "Exchange rate risks and asset prices in a small open economy" by A. Derviz, March 2004.

315 "Option-implied asymmetries in bond market expectations around monetary policy actions of the ECB" by S. Vähämaa, March 2004.

316 "Cooperation in international banking supervision" by C. Holthausen and T. Rønde, March 2004.

317 "Fiscal policy and inflation volatility" by P. C. Rother, March 2004.

318 "Gross job flows and institutions in Europe" by R. Gómez-Salvador, J. Messina and G. Vallanti, March 2004.

319 "Risk sharing through financial markets with endogenous enforcement of trades" by T. V. Köppl, March 2004.

320 "Institutions and service employment: a panel study for OECD countries" by J. Messina, March 2004.

321 "Frequency domain principal components estimation of fractionally cointegrated processes" by C. Morana, March 2004.

322 "Modelling inflation in the euro area" by E. S. Jansen, March 2004. 
